\title{
Hidrogeoquímica do Sistema Aquífero Cristalino no sul do estado do Espírito Santo - Brasil
}

\author{
Hydrogeochemistry of the Crystalline Aquifer System in the \\ South of the state of Espirito Santo - Brazil
}

\author{
Mirna Aparecida Neves ${ }^{1} \odot$, Matheus Serri Moulin de Oliveira ${ }^{2} \odot$, Salomão Silva Calegari ${ }^{2} \odot$, \\ Reginaldo Antonio Bertolo 3 (D), Ricardo César Aoki Hirata 3 (D), Fabrício de Andrade Caxito ${ }^{2}$ (1) \\ 'Universidade Federal do Espírito Santo - UFES, Centro de Ciências Exatas, Naturais e da Saúde - CCENS, Alto Universitário, \\ s/n, Guararema, CEP: 29500-000, Alegre, ES, BR (mirnaan@gmail.com) \\ 2Universidade Federal de Minas Gerais - UFMG, Programa de Pós-Graduação em Geologia e Centro de Pesquisa Manoel \\ Teixeira da Costa, Belo Horizonte, MG, BR (matheusserri@hotmail.com; salomaocalegari@hotmail.com; caxito@ufmg.br) \\ 3Universidade de São Paulo - USP, Instituto de Geociências, São Paulo, SP, BR (bertolo@usp.br; rhirata@usp.br)
}

Recebido em 13 de abril de 2020; aceito em 10 de setembro de 2021.

\begin{abstract}
Resumo
A demanda por água subterrânea no estado do Espírito Santo vem crescendo consideravelmente frente aos eventos de escassez que marcaram os últimos anos. No entanto, a carência de conhecimentos hidrogeológicos compromete a locação de poços e a previsão da qualidade das águas, especialmente nos terrenos de rochas cristalinas. Este trabalho teve como objetivo uma avaliação hidrogeoquímica e da qualidade da água subterrânea do Sistema Aquífero Cristalino na Bacia Hidrográfica do Rio Itapemirim (BHRI), situada no sul do estado do Espírito Santo, descrevendo as variações composicionais e os condicionantes que influenciam a qualidade da água subterrânea. A compartimentação litológica e geomorfológica da bacia e as condições climáticas são os fatores que influenciam na hidrogeoquímica em escala regional, enquanto o uso e a ocupação do solo exercem influência pontual. Na porção da Alta BHRI, com relevo acidentado e predomínio de atividades agropecuárias, ocorrem principalmente águas bicarbonatadas cálcicas e bicarbonatadas cálcicas-magnesianas, pouco mineralizadas comparativamente à porção central da bacia, com composição química governada essencialmente pelo intemperismo das rochas silicáticas. Embora sejam águas de boa qualidade, alterações locais podem ocorrer em razão do nitrato proveniente de atividades antrópicas. Na porção da Média BHRI, com menores altitudes e relevo mais suave, as águas são predominantemente bicarbonatadas sódicas e cloretadas sódicas, com maior mineralização em relação à porção alta da bacia em razão da contribuição de rochas silicáticas em associação com litotipos carbonáticos, como mármores e calciossilicáticas. Nessa porção da bacia, as condições climáticas, com temperaturas mais altas e menor umidade do ar na área central da bacia, topograficamente mais rebaixada, também podem contribuir com o enriquecimento mineral em decorrência da evaporação da água que infiltra no solo.
\end{abstract}

Palavras-chave: Água subterrânea; Aquíferos fraturados; Bacia Hidrográfica do Rio Itapemirim.

\begin{abstract}
The groundwater demand in the state of Espírito Santo (Brazil) has been growing considerably due to the events of drought in recent years. However, the lack of hydrogeological knowledge compromises water-well location and the prediction of the quality of water, mainly where crystalline rocks occur. This work aimed to evaluate the hydrogeochemical and groundwater quality of the Crystalline Aquifer System in the Itapemirim River Watershed (BHRI), located in the Southern part of Espírito Santo, describing the compositional variations and the conditioners that control groundwater quality. The lithological and geomorphological compartmentalization of the watershed in addition to climatic conditions are the factors that influence the groundwater geochemistry at a regional scale, while the land use and occupation exert a local influence. In the Upper BHRI portion, with steep relief and predominance of farming, there are mainly low-mineralized calcic bicarbonated and calcic-magnesian bicarbonated waters with components provided by the weathering of metamorphic and igneous silicate rocks. Although these are good quality waters, local changes can occur due to the presence of nitrate from human activities. In the Medium BHRI portion, with softer relief and lower topographic altitudes, groundwater is mainly of sodium chlorinated and sodium bicarbonated types, more mineralized due to the contribution of silicate rocks in association with carbonated lithotypes, such as marbles and calcium-silicate rocks. The climatic conditions, with higher temperatures and lower air humidity in the central area of the basin, which is topographically lower, can also contribute to mineral enrichment due to the evaporation of water in the soil.
\end{abstract}

Keywords: Groundwater; Fractured aquifers; Itapemirim River Watershed. 


\section{INTRODUÇÃO}

O Sistema Aquífero Cristalino (SAC) ocorre em regiões de rochas predominantemente ígneas e metamórficas e é composto de dois subsistemas: o meio fraturado, em que a água percola nas descontinuidades da rocha sã, e o manto de intemperismo, que se comporta como um aquífero de porosidade primária (Banks et al., 2009; Foster, 2012). A rocha sã fraturada é considerada um meio eventualmente muito transmissivo, enquanto o manto de intemperismo sobrejacente, um meio poroso com alta capacidade de armazenamento (Lachassagne et al., 2011).

Apesar de ocorrer em grande parte da superfície terrestre, o comportamento da água subterrânea em terrenos de rochas cristalinas é ainda pouco compreendido em razão do caráter heterogêneo e anisotrópico de suas propriedades hidráulicas (Singhal e Gupta, 2010). Uma ferramenta que pode auxiliar no entendimento do fluxo subterrâneo é o estudo das características hidrogeoquímicas, cujas variações podem indicar propriedades importantes do aquífero, inclusive caminhos preferenciais de fluxo (Roques et al., 2014). Tal conhecimento é relevante em muitos países com alta demanda por água subterrânea (Subramani et al., 2010; Singaraja et al., 2014), onde, além dos processos de interação água-rocha, outros fatores, como sobre-explotação de aquíferos, destinação incorreta de efluentes industriais e de resíduos sólidos, uso intenso de fertilizantes e esgoto doméstico, interferem na qualidade da água subterrânea (Machiwal e Jha, 2015; Raju et al., 2016).

No Brasil, ainda existem grandes áreas onde a hidrogeoquímica dos terrenos cristalinos é completamente desconhecida, com exceção de alguns estudos realizados nas regiões Nordeste (e.g. Gomes e Cavalcante, 2015) e Sul-Sudeste (e.g. Menezes et al., 2008; Iritani et al., 2011; Ezaki et al., 2014). No estado do Espírito Santo, embora a maior parte do arcabouço geológico seja composto de rochas cristalinas, ainda não há conhecimento sólido sobre a qualidade da água subterrânea. Nessa região, a água para abastecimento público, residencial ou industrial provém de fontes de água superficial ou por meio de poços tubulares rasos, que explotam água do manto de intemperismo. Contudo, a escassez e os prolongados períodos de estiagem dos últimos anos têm induzido a perfuração de poços tubulares profundos, que penetram a rocha sã para explotar o sistema fraturado. O desconhecimento das características hidrogeológicas regionais aumenta as chances de poços secos, de baixa produção ou com água de má qualidade.

O objetivo deste trabalho foi descrever as características hidrogeoquímicas do SAC na área de abrangência da Bacia Hidrográfica do Rio Itapemirim (BHRI), localizada no sul do Espírito Santo, região Sudeste do Brasil (Figura 1), buscando-se identificar as variações composicionais e os condicionantes da qualidade da água subterrânea captada em poços tubulares profundos.

\section{MATERIAL E MÉTODOS}

Amostras de água subterrânea foram coletadas em 36 poços tubulares profundos que explotam o SAC (Figura 2), em campanhas realizadas nas estações de chuva e de estiagem nos anos de 2014, 2015 e 2016, totalizando 76 amostras. Em virtude da distribuição dos poços disponíveis para coleta de água, foram estudadas apenas as porções da Média e da Alta BHRI.

Em campo, foram medidos os parâmetros físicos e químicos da água subterrânea: potencial hidrogeniônico $(\mathrm{pH})$, condutividade elétrica (CE) e sólidos totais dissolvidos (STD), por meio de um medidor multiparâmetro portátil de campo devidamente calibrado e com certificado de qualidade, apropriado para os intervalos: $\mathrm{pH}$ entre 0 e 14 (resolução de 0,01 ); CE entre $0,1 \mu{\mathrm{S} . \mathrm{cm}^{-1}}^{-1} 500 \mathrm{mS}_{\mathrm{cm}}{ }^{-1}$; e STD entre 0,1 $\mathrm{mg} . \mathrm{L}^{-1}$ e $300 \mathrm{~g} . \mathrm{L}^{-1}$. A turbidez foi medida por meio de um turbidímetro portátil de campo calibrado, com range de 0,00 a 1.000 UNT. As amostras destinadas às análises de cátions foram filtradas em membranas de acetato celulose de 0,45 $\mu \mathrm{m}$, acidificadas com ácido nítrico ultrapuro até $\mathrm{pH}<2 \mathrm{e}$ armazenadas em frascos de polietileno, sob temperatura de $4^{\circ} \mathrm{C}$. As amostras para análise de ânions foram congeladas e as amostras para medição de alcalinidade foram armazenadas em ambiente refrigerado, evitando-se o contato com o ar. A alcalinidade total foi medida por titulação com $\mathrm{H}_{2} \mathrm{SO}_{4}$ a 0,1 ou 0,01 mol. $\mathrm{L}^{-1}$ e indicador misto. As análises dos cátions (sódio, potássio, cálcio, magnésio, lítio e amônia) e dos ânions (sulfato, fosfato, cloreto, nitrato, nitrito, brometo e fluoreto) foram realizadas por cromatografia iônica de alta resolução (método $S M E W W$ 4110C). Na análise de dados foram consideradas apenas as amostras com erro de balanço iônico menor do que $10 \%$. Os resultados dos parâmetros que constituem padrão de potabilidade foram comparados com os valores máximos permitidos (VMPs) em águas destinadas ao consumo por humanos, conforme a Agência Nacional de Vigilância Sanitária (ANVISA) em sua Portaria de Consolidação n ${ }^{\circ}$ 5/2017 (Brasil, 2017), após revogação da Portaria n ${ }^{\circ}$ 2.914/2011.

O programa AquaChem 2011.1/Schlumberger foi utilizado no tratamento de dados para construção dos diagramas de Piper e Stiff. Nessa parte do trabalho, as amostras com mais de $10 \%$ de nitrato no balanço iônico foram excluídas do conjunto por serem consideradas alteradas por influência antrópica. Os layouts de mapas foram confeccionados por meio do software ArcGIS ${ }^{\circledast}$ 10.2/ESRI.

\section{ÁREA DE ESTUDOS}

A BHRI é uma das principais redes hidrográficas do Espírito Santo, cobrindo praticamente toda a porção sul do estado e uma pequena área do sudeste de Minas Gerais (ANA, 
2010); possui cerca de $6.014 \mathrm{~km}^{2}$ e abrange 17 municípios capixabas e um mineiro.

As atividades econômicas na BHRI são relacionadas à agropecuária, como o plantio de café, hortaliças, leguminosas e a bovinocultura extensiva. O estado participa notavelmente no setor de beneficiamento de rochas ornamentais, principalmente o município de Cachoeiro de Itapemirim, considerado o maior polo produtor e exportador do Brasil (Sardou-Filho et al., 2013). Essa cidade concentra 36,27\% da população sul capixaba, que é de cerca de 524.000 habitantes (IBGE, 2010).

\section{Clima}

O clima da região é o tropical governado pelo relevo, com duas estações bem definidas: a chuvosa, nos meses de novembro a abril, e a seca. A média anual de precipitação na BHRI varia entre $1.000 \mathrm{~mm}$, na porção menos chuvosa da bacia, e cerca de $2.000 \mathrm{~mm}$, nos locais mais chuvosos (INCAPER, 2018). Importante relatar que, na época de realização deste trabalho, entre 2014 e 2016, todo o estado do Espírito Santo passou por um déficit hídrico, com cerca de 25 a $50 \%$ menos chuvas do que as médias históricas (INCAPER, 2016).

Um fragmento do mapa climático (SEPLAN, 1999) mostra a distribuição das zonas climáticas na BHRI, que dividem a região em terras quentes (com temperatura média do mês mais frio de $11,8^{\circ} \mathrm{C}$ e temperatura média do mês mais quente de $\left.34,0^{\circ} \mathrm{C}\right)$, de temperaturas amenas $\left(9,4\right.$ e $\left.30,7^{\circ} \mathrm{C}\right)$, e terras frias $\left(7,3\right.$ e $\left.27,8^{\circ} \mathrm{C}\right)$, em associação com terras secas, transicionais e chuvosas (Figura 3). Essa distribuição regional das temperaturas e das chuvas é controlada pelo relevo, com porções montanhosas, mais frias e chuvosas, no entorno da porção central da bacia, mais quente e seca (INCAPER, 2018).

\section{Geologia e geomorfologia}

A área de estudo está incluída no domínio geotectônico da Província Mantiqueira, na zona sul da faixa de dobramentos Araçuaí (Gradim et al., 2014), compreendendo principalmente o Embasamento Pré-Cambriano, composto de rochas

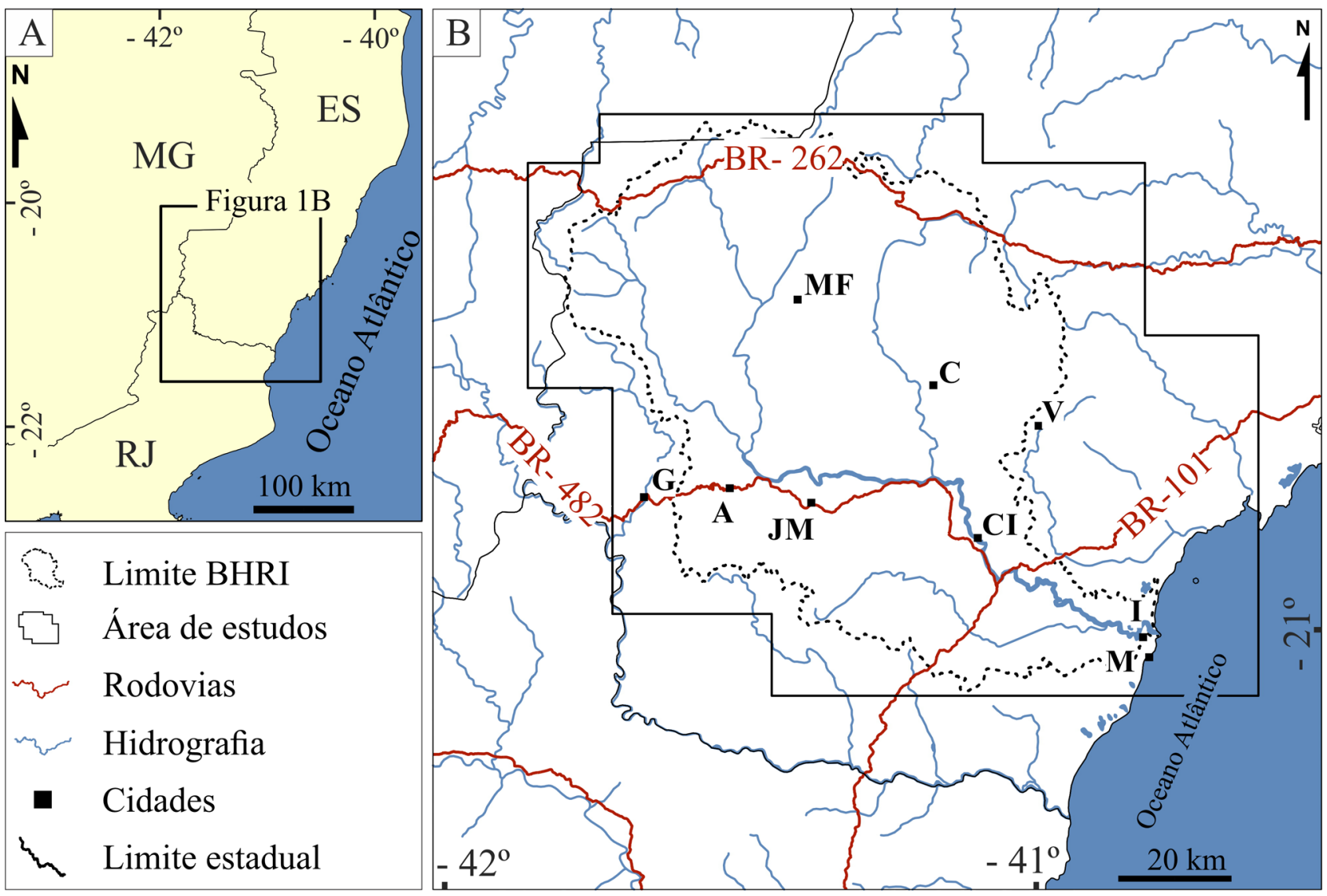

BHRI: Bacia Hidrográfica do Rio Itapemirim; cidades: A: Alegre; C: Castelo; G: Guaçuí; Cl: Cachoeiro de Itapemirim; I: Itapemirim; JM: Jerônimo Monteiro; M: Marataízes; MF: Muniz Freire; V: Venda Nova do Imigrante.

Figura 1. (A) Localização da porção estudada na região Sudeste do Brasil; (B) localização da área de estudos em relação à Bacia Hidrográfica do Rio Itapemirim. 
metamórficas como gnaisses, migmatitos, charnoquitos e milonitos, além de rochas ígneas granitoides e gabroicas cambrianas (Vieira et al., 2014). Ocorrem também, de forma mais restrita, coberturas sedimentares neogênicas da Formação Barreiras, e quaternárias, representadas principalmente por aluviões. O mapa geológico apresentado na Figura 4 mostra

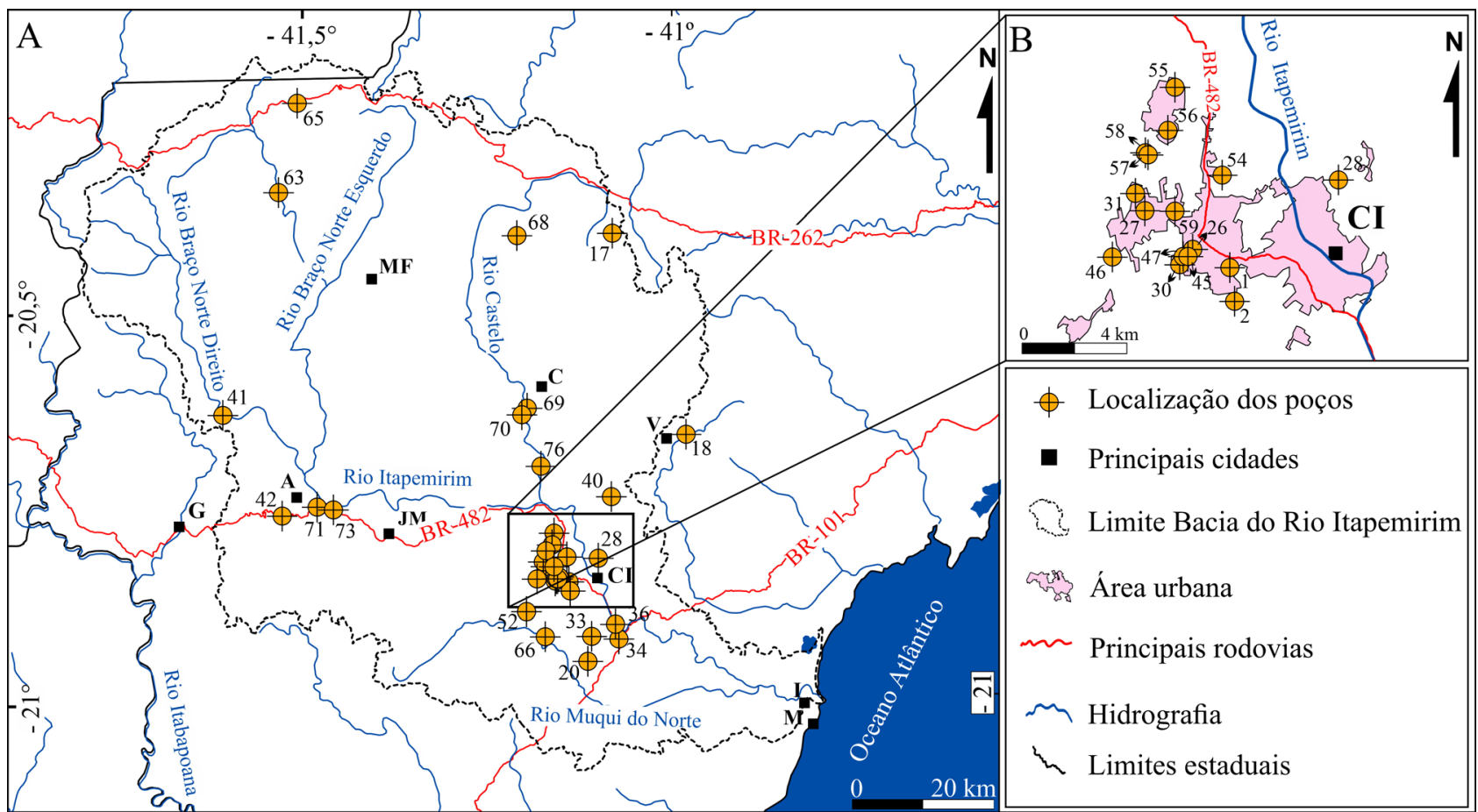

Fonte: banco de dados vetoriais do Geobases (2002).

A: Alegre; C: Castelo; G: Guaçuí; Cl: Cachoeiro de Itapemirim; I: Itapemirim; JM: Jerônimo Monteiro; M: Marataízes; MF: Muniz Freire; V: Venda Nova do Imigrante. Figura 2. (A) Localização dos poços tubulares profundos que constituíram os pontos de coleta de amostras representativas do Sistema Aquífero Cristalino na Bacia Hidrográfica do Rio Itapemirim; (B) detalhe no município de Cachoeiro de Itapemirim (ao lado do símbolo dos poços está a numeração deles utilizada no trabalho).
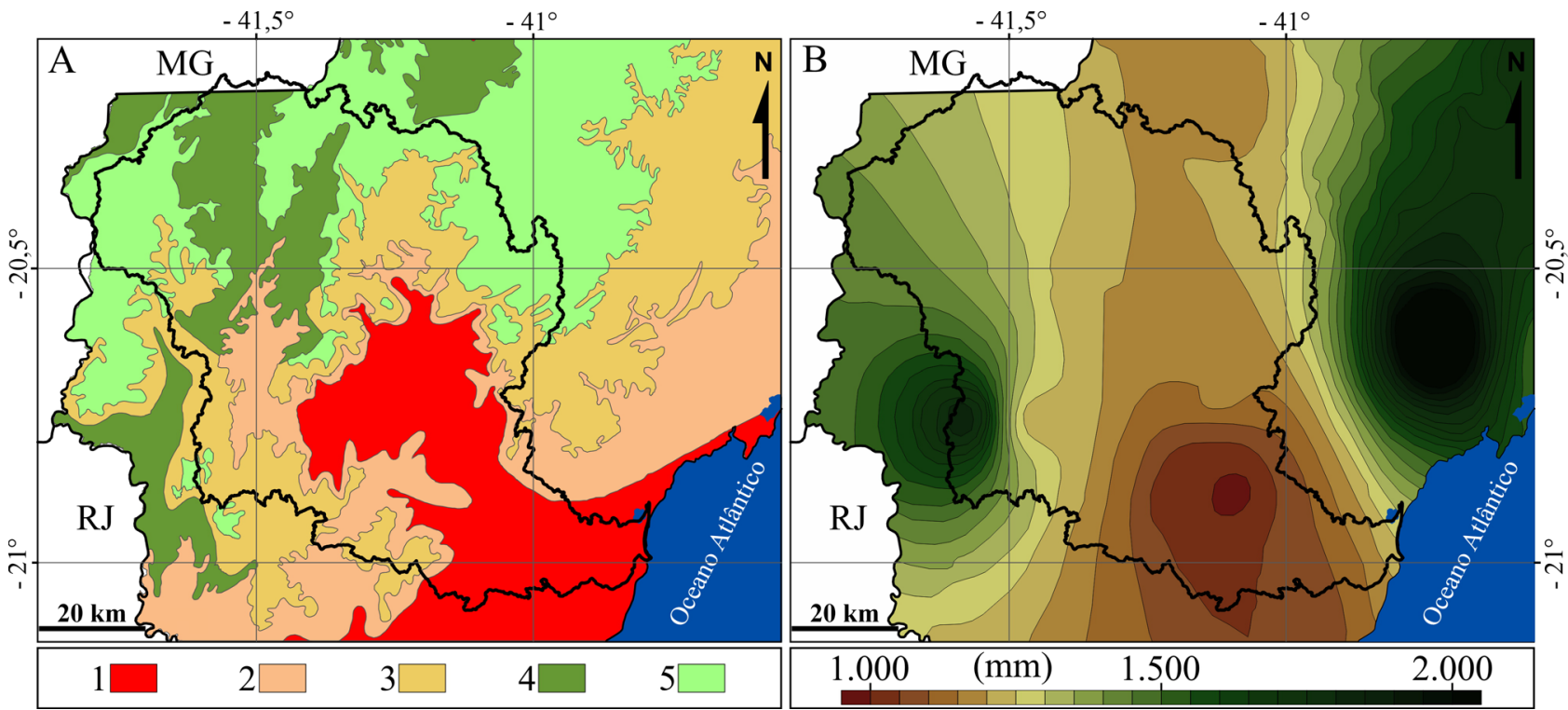

1: terras quentes e secas; 2: terras quentes e de transição chuvosas-secas; 3: terras de temperaturas amenas, chuvosas; 4: terras de temperaturas amenas, chuvosas-secas; 5: terras frias e chuvosas.

Figura 3. (A) Mapa de zoneamento climático da região sul do estado do Espírito Santo (adaptado de SEPLAN, 1999); (B) mapa de precipitação total observada (adaptado de INCAPER, 2018). 
a distribuição das unidades geológicas do Embasamento mapeadas por Vieira et al. (2014) e a delimitação das coberturas sedimentares conforme Peixoto-Oliveira et al. (2018).

As diferenças litológicas e estruturais proporcionam variações geomorfológicas ao longo da bacia que podem ser divididas em três compartimentos morfoestruturais: Mantiqueira, Cachoeiro e Litorâneo, respectivamente denominados aqui como as porções da Alta, Média e Baixa BHRI (Peixoto-Oliveira et al., 2018) (Figura 5).

Na porção da Alta BHRI, predominam gnaisses e granitoides, compondo relevo escarpado de morros, morrotes e serras. Estruturas geológicas como foliação, extensas zonas de cisalhamento e zonas fraturadas controlam o relevo, onde são comuns os vales encaixados. Na Média
BHRI, junto aos gnaisses e granitoides, ocorrem lentes de mármore e corpos de rochas calciossilicáticas intercaladas entre os demais litotipos. Essa região é caracterizada pela menor altitude com relação ao seu entorno, com mares de morros e vales aplainados. A Baixa BHRI é constituída de rochas gnáissicas, com coberturas de sedimentos da Formação Barreiras, além dos fluviais e litorâneos; e as formas do relevo são suaves, com morros, colinas, tabuleiros e amplas planícies aluviais. As coberturas sedimentares possuem maior expressão nas porções da Média e da Baixa BHRI, que são áreas de agradação, enquanto a Alta BHRI constitui uma área de degradação, fornecendo sedimentos para as porções mais baixas (Peixoto-Oliveira et al., 2018).

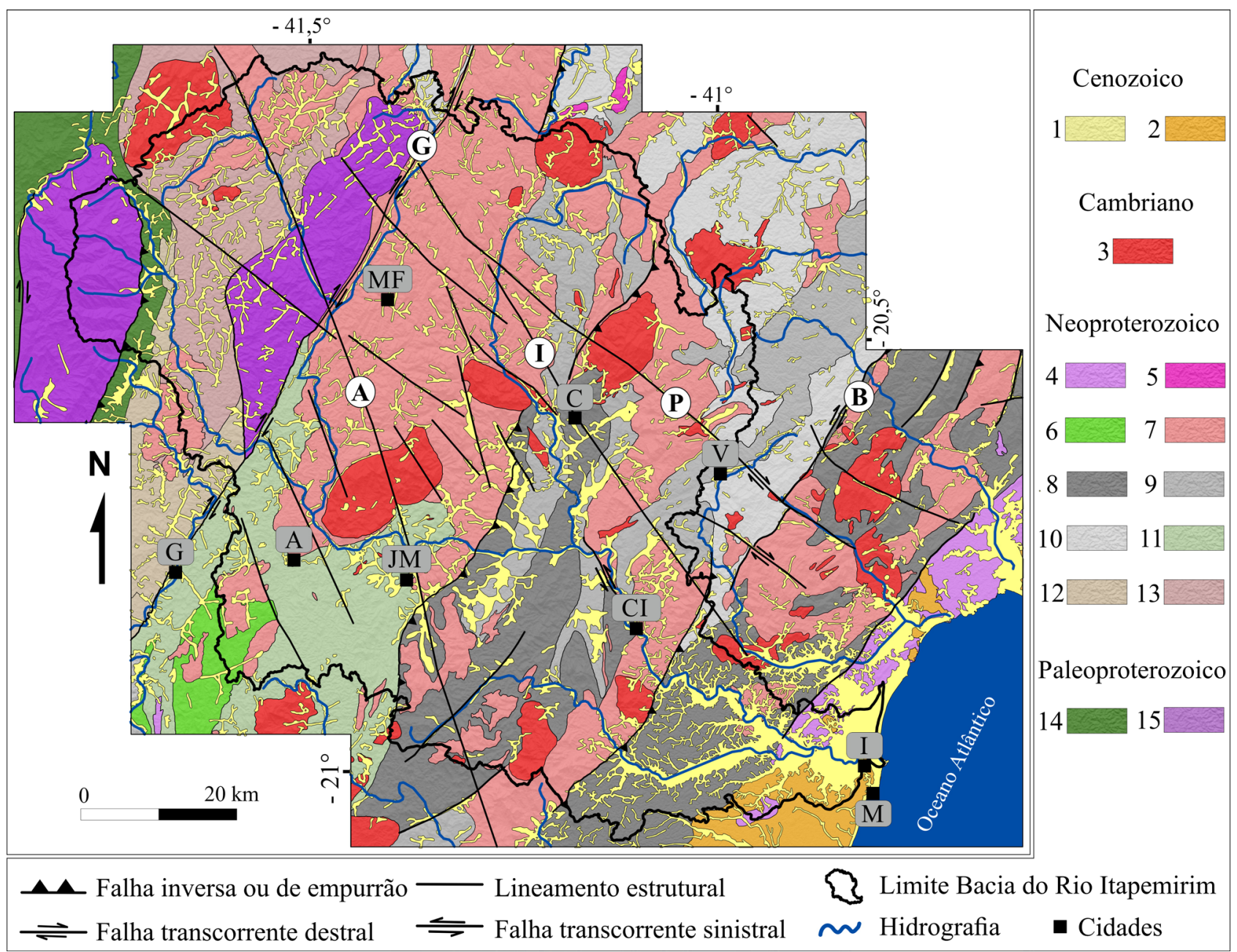

Fonte: modelo digital de elevação ASTER GDEM v2: NASA e METI (2011).

Zonas de Cisalhamento (ZC): G: ZC Guaçuí; B: ZC Batatais; lineamentos: A: Alegre; I: Itaoca; P: Piúma; cidades: A: Alegre; C: Castelo; G: Guaçuí; Cl: Cachoeiro de Itapemirim; I: Itapemirim; JM: Jerônimo Monteiro; M: Marataízes; MF: Muniz Freire; V: Venda Nova do Imigrante; litotipos: 1: sedimentos quaternários; 2: Fm. Barreiras; 3: maciços granitoides; 4: charnoquitos; 5: granitoides pouco foliados; 6: ortogranulitos; 7: granitoides foliados a gnáissicos: ortognaisses, tonalitos e granodioritos; 8: gnaisses com intercalação de quartzitos, calciossilicáticas e anfibolitos; 9: gnaisses com intercalações de anfibolitos, rochas calciossilicáticas e mármores; 10: gnaisses quartzosos; 11: gnaisses e anfibolitos; 12: gnaisses e kinzingitos; 13: biotita xistos com intercalações de metavulcânicas e gnaisses quartzíticos; 14: gnaisses e gnaisses miloníticos; 15: granulitos.

Figura 4. Mapa geológico da Bacia Hidrográfica do Rio Itapemirim com relevo sombreado sob azimute $315^{\circ}$, unidades do Embasamento Cristalino segundo Vieira et al. (2014) e coberturas sedimentares conforme Peixoto-Oliveira et al. (2018). 


\section{RESULTADOS}

\section{Distribuição dos sistemas aquíferos na Bacia Hidrográfica do Rio Itapemirim}

O SAC ocupa cerca de $88 \%\left(5.228 \mathrm{~km}^{2}\right)$ da área da BHRI. Ele compreende as rochas cristalinas fraturadas, representadas frequentemente por gnaisses e granitoides, e o aquífero associado ao manto de alteração intempérica próximo à superfície. O SAC abrange as porções da Alta, da Média e da Baixa BHRI, e suas características são controladas pelos fatores geológicos, estruturais e geomorfológicos do Embasamento Cristalino. As abordagens deste artigo referem-se à água subterrânea presente na rocha fraturada pertencente ao SAC (Figura 6).

Sobreposto ao SAC, ocorre também, de forma mais localizada, o Sistema Aquífero Sedimentar (SAS). O SAS abrange $12 \%\left(719 \mathrm{~km}^{2}\right)$ da área da bacia e é composto, nas porções da Alta e da Média BHRI, dos sedimentos aluviais e coluviais presentes nas planícies fluviais, nos fundos de vales e nas encostas de morros. Na porção da Baixa BHRI, especialmente na região litorânea, ocorre nas coberturas sedimentares da Formação Barreiras e nos sedimentos costeiros ou litorâneos, além dos depósitos fluviocoluviais.

Embora o SAS seja um aquífero de porosidade intergranular, sua distribuição é controlada pelas estruturas geológicas da área, como zonas de fraturas (juntas e falhas), que compartimentam o terreno. Isso fica claro quando se observa a forma dos corpos sedimentares nas diversas porções da bacia. Na porção da Baixa BHRI, os corpos sedimentares são formas com aspecto dendrítico e de ocorrência mais ampla do que na porção da Média BHRI, onde os corpos são irregulares e relativamente menos frequentes do que na porção baixa. Na Alta BHRI, os depósitos sedimentares ocorrem como formas retilíneas e alongadas, por estarem fortemente controlados por descontinuidades (principalmente zonas fraturadas) que compõem os vales encaixados das drenagens, como é típico dos terrenos de rocha cristalina.

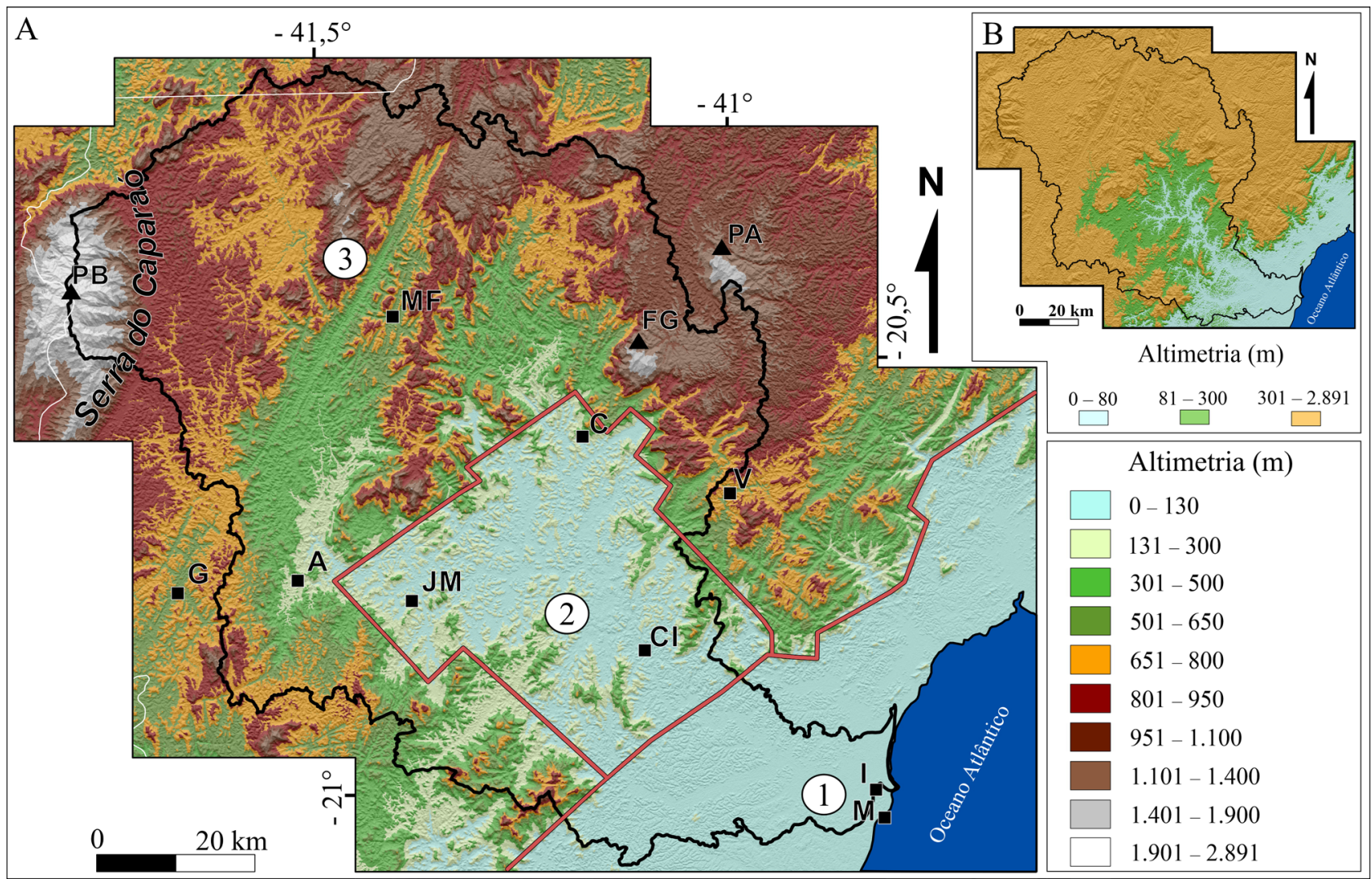

Fonte: modelo digital de elevação ASTER GDEM v2: NASA e METI (2011).

A: Alegre; C: Castelo; G: Guaçuí; Cl: Cachoeiro de Itapemirim; I: Itapemirim; JM: Jerônimo Monteiro; M: Marataízes; MF: Muniz Freire; V: Venda Nova do Imigrante; elevações topográficas: PB: Pico da Bandeira; FG: Forno Grande; PA: Pedra Azul.

Figura 5. (A) Variação altimétrica da área e delimitação dos setores da (3) Alta, (2) Média e (1) Baixa Bacia Hidrográfica do Rio Itapemirim plotado sobre relevo sombreado com azimute de $315^{\circ}$, os quais coincidem com os compartimentos Mantiqueira, Cachoeiro e Litorâneo de Peixoto-Oliveira et al. (2018); (B) altimetria simplificada plotada sobre relevo sombreado com azimute de $315^{\circ}$. 


\section{Uso da água subterrânea na Bacia Hidrográfica do Rio Itapemirim}

O cadastro de poços organizado neste trabalho e as visitas de campo realizadas mostram que mais da metade dos poços $(60 \%)$ capta água na BHRI destinada ao uso industrial (Figura 7), essencialmente voltado à indústria de beneficiamento de rochas ornamentais; esse tipo de uso é concentrado na área urbana da sede do município de Cachoeiro de Itapemirim. Em segundo lugar, vem o uso para consumo por humanos $(29 \%)$, por meio de abastecimento público, rural ou doméstico. O uso para dessedentação de animais em granjas e a irrigação são minoritários, com 8 e $3 \%$, respectivamente.

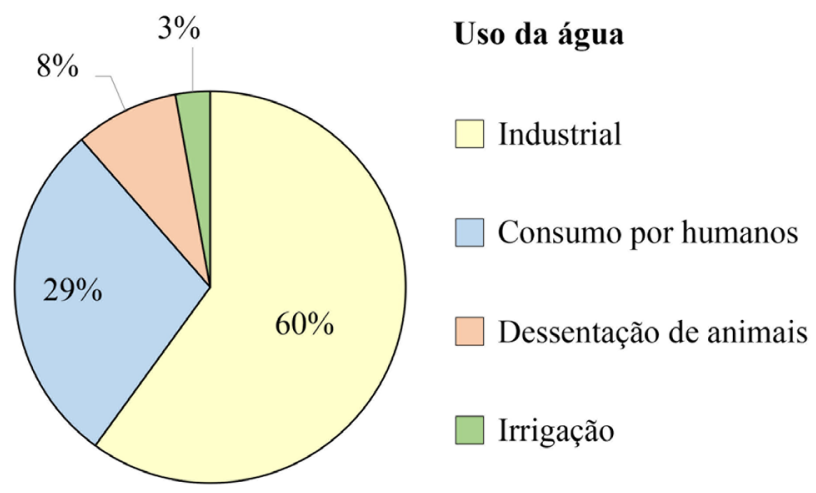

Figura 7. Usos a que se destinam as águas subterrâneas na Bacia Hidrográfica do Rio Itapemirim.

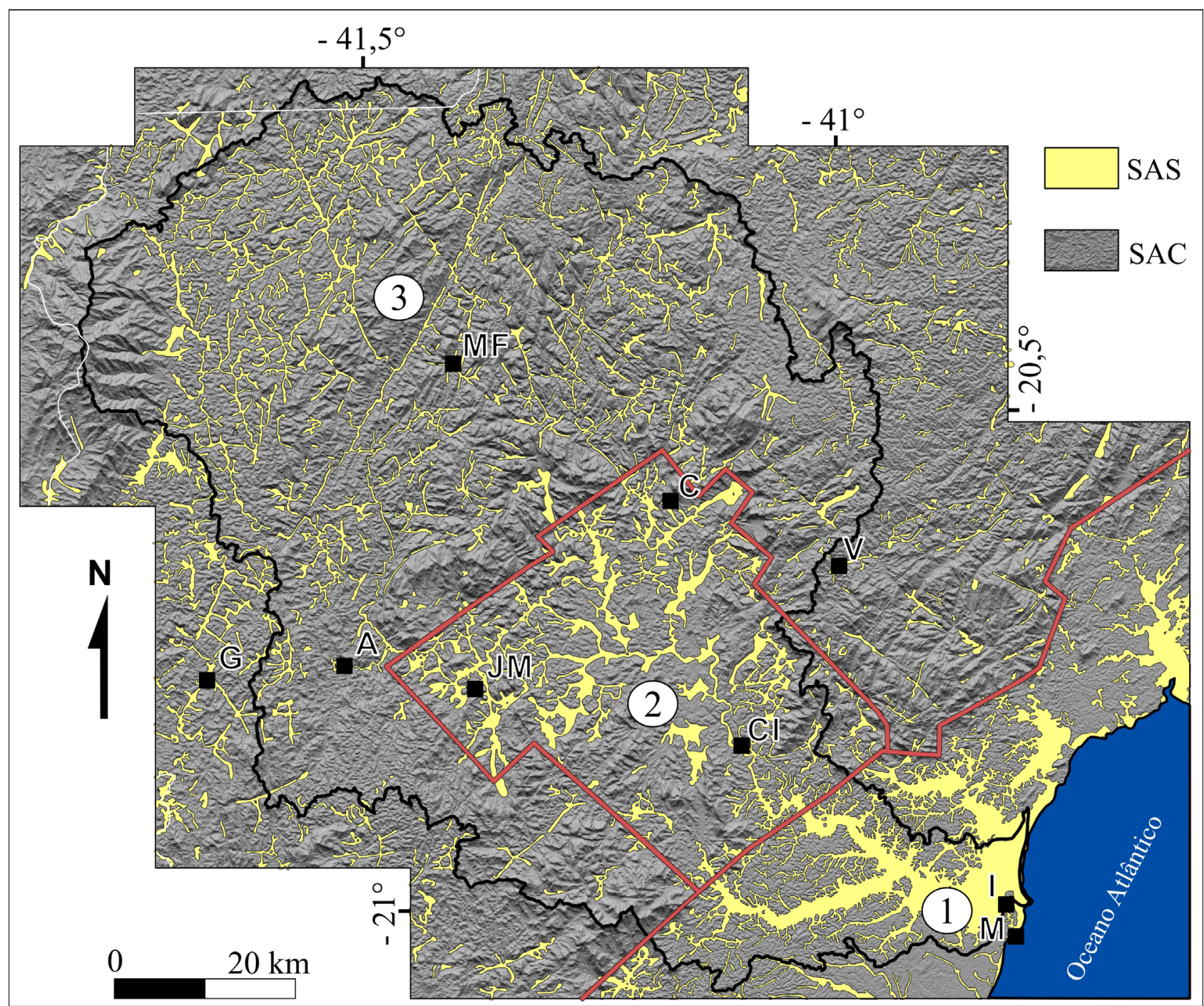

Fonte: modelo digital de elevação ASTER GDEM v2: NASA e METI (2011).

A: Alegre; C: Castelo; G: Guaçú; Cl: Cachoeiro de Itapemirim; I: Itapemirim; JM: Jerônimo Monteiro; M: Marataízes; MF: Muniz Freire; V: Venda Nova do Imigrante; compartimentos: 3: Alta BHRI; 2: Média BHRI; 1: Baixa BHRI; SAS: Sistema Aquífero Sedimentar; SAC: Sistema Aquífero Cristalino.

Figura 6. Distribuição espacial dos sistemas aquíferos da Bacia Hidrográfica do Rio Itapemirim plotada sobre relevo sombreado com azimute de $315^{\circ}$. 


\section{Características hidroquímicas das águas subterrâneas na Bacia Hidrográfica do Rio Itapemirim}

Os parâmetros hidrogeoquímicos medidos na BHRI nas estações de chuvas (verão) e de estiagem (inverno) não apresentaram variações significativas (Figura 8), ao contrário do que relatam trabalhos conduzidos em terrenos cristalinos de outros países, como França (Roques et al., 2014) e Índia (e.g. Negrel et al., 2011; Machiwal e Jha, 2015; Raju et al., 2016). É possível que a não observação de tais variações na BHRI seja decorrente da amostragem em um ano hidrológico anômalo, com períodos secos mais longos seguidos de períodos chuvosos com precipitação abaixo do normal, conforme descrito anteriormente.

Por tal homogeneidade, o tratamento de dados apresentado neste trabalho considera, para cada ponto de medida, a média dos valores obtidos nas campanhas de coleta (Tabela 1). Além dos valores médios, a Tabela 1 mostra também o VMP para alguns parâmetros, conforme a Portaria $\mathrm{n}^{\circ} 05$ de 28 de setembro de 2017 do Ministério da Saúde (Brasil, 2017).
Cerca de $10 \%$ das amostras analisadas apresentaram turbidez acima do VMP, provavelmente em função de problemas construtivos e falta de manutenção dos poços. ACE varia consideravelmente, desde valores muito baixos, que refletem a infiltração direta da água da chuva, até valores extremos, indicando enriquecimento mineral da água subterrânea em determinada região da BHRI. Os valores de $\mathrm{pH}$ estão dentro do range esperado para águas subterrâneas, com exceção de um valor extremo igual a 8,10 no poço 31 , onde o $\mathrm{Cl}$ também ocorre em concentração elevada.

A concentração de $\mathrm{Cl}^{-}$está acima do $\mathrm{VMP}$ em aproximadamente $8 \%$ dos poços. Em terrenos de rochas cristalinas de áreas continentais, a presença desse íon na água subterrânea pode estar relacionada à infiltração de efluentes urbanos ou à evaporação da água que infiltra no solo. Porém, é importante observar que não há associação entre amostras com altos valores de $\mathrm{Cl}^{-}$e de $\mathrm{NO}_{3}^{-}$(Tabela 2), sendo este estritamente associado a atividades antrópicas, o que desvincula, portanto, o alto $\mathrm{Cl}^{-}$da fonte antrópica na bacia estudada.

Os mapas de distribuição espacial de $\mathrm{NO}_{3}^{-} \mathrm{e} \mathrm{Cl}^{-}$(Figura 9) mostram a baixa correlação espacial entre esses parâmetros.

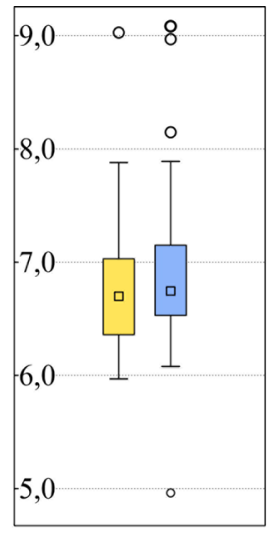

$\mathrm{pH}$

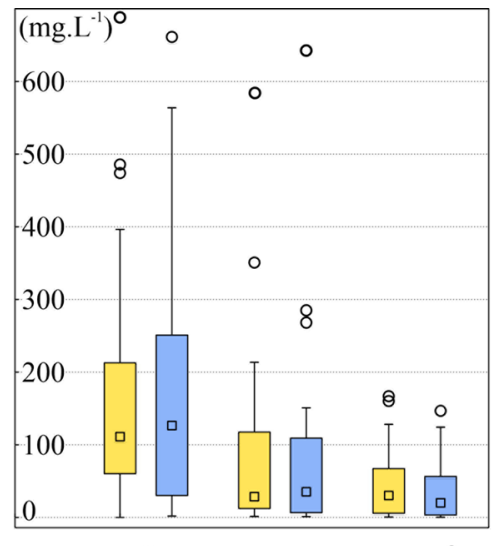

$\mathrm{Cl}^{-}$
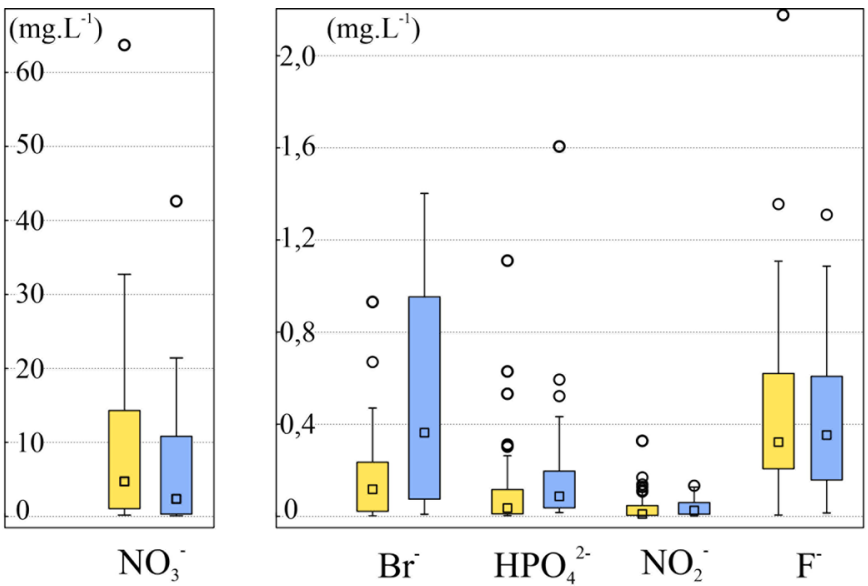

$\mathrm{Br}$

$\mathrm{F}^{-}$

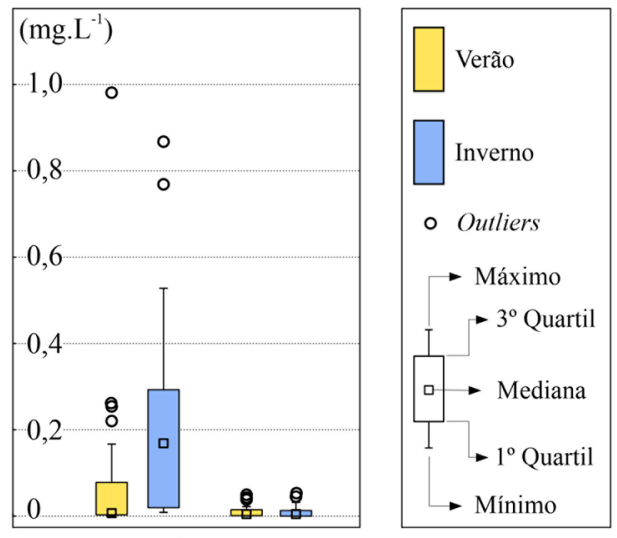

$\mathrm{NH}_{4}^{+} \quad \mathrm{Li}^{+}$

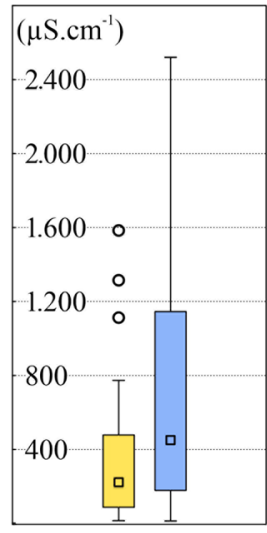

$\mathrm{CE}$

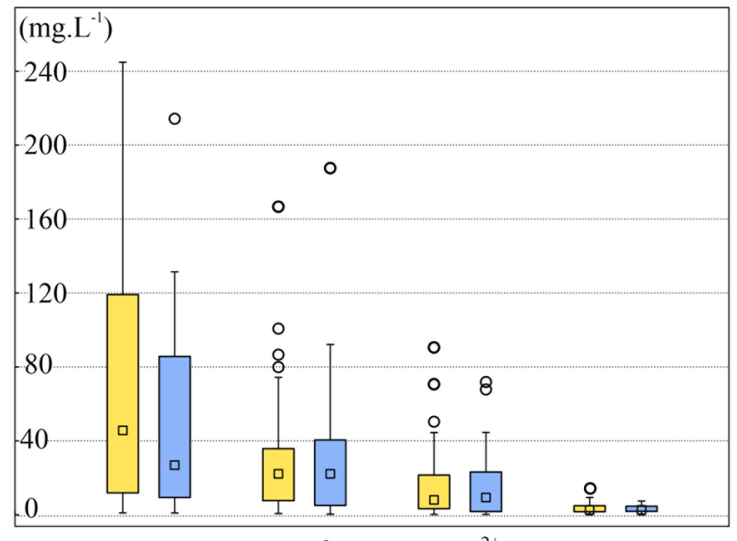

$\mathrm{Na}^{+}$
$\mathrm{Ca}^{2+}$
$\mathrm{Mg}^{2+}$
$\mathrm{K}^{+}$

CE: condutividade elétrica.

Figura 8. Distribuição de valores dos parâmetros de qualidade da água subterrânea na Bacia Hidrográfica do Rio Itapemirim, no verão e no inverno. 


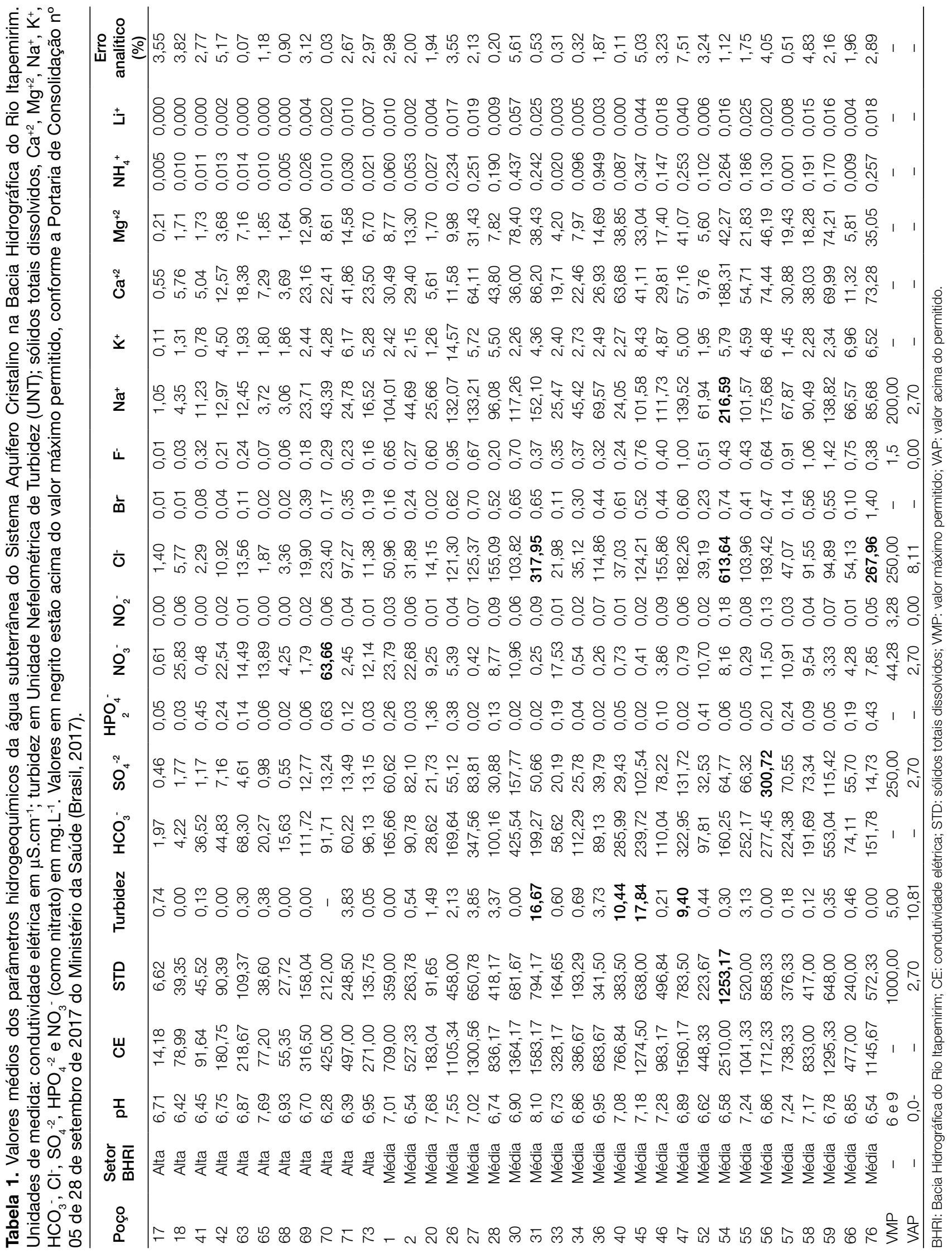


Os altos valores de $\mathrm{Cl}^{-}$ocorrem sempre na porção da Média BHRI, enquanto a concentração de $\mathrm{NO}_{3}^{-}$é alta em locais dispersos ao longo da bacia. Por outro lado, $\mathrm{o} \mathrm{Cl}$ - possui forte correlação positiva com o $\mathrm{Na}^{+}$e o Ca ${ }^{+2}$ (Tabela 2), que denotam origem natural por dissolução de rochas e possível enriquecimento por evaporação da água no solo. Igualmente se associam com forte correlação positiva o $\mathrm{HCO}_{3}^{-}, \mathrm{o} \mathrm{Ca}^{+2}, \mathrm{o} \mathrm{Mg}^{+2} \mathrm{e}$ o $\mathrm{Na}^{+}$, os quais também podem advir de fontes naturais como as rochas ígneas e metamórficas que compõem o arcabouço geológico da BHRI. O intemperismo de minerais silicáticos e de carbonatos, a partir de reações de troca catiônica, regula a presença desses componentes em muitas regiões de rochas cristalinas (Srinivasamoorthy et al., 2008; Subramani et al., 2010). A presença de $\mathrm{Mg}^{+2}$ na água subterrânea de terrenos cristalinos costuma ser vinculada ao intemperismo de mármores dolomíticos ou de rochas máfico-ultramáficas, enquanto o $\mathrm{Na}^{+}$pode ser atribuído ao intemperismo de feldspatos em rochas como charnoquitos e hornblenda gnaisses (Thivya et al., 2015).

$\mathrm{O} \mathrm{SO}_{4}^{-2}$ possui concentração anômala no poço 56 , construído para atender a um parque de beneficiamento de rochas ornamentais. Sua correlação é forte com o $\mathrm{HCO}_{3}^{-}$(Tabela 2), e tais componentes podem ser fornecidos por atividades de mineração ou lançamentos de esgotos, mas também por fontes naturais (Hem, 1985), como paragnaisses (Bucher et al., 2009). Embora não existam rochas sulfetadas na área para prover $\mathrm{SO}_{4}^{-2}$ de forma significativa para a água subterrânea, importante observar que sua correlação também é forte com o $\mathrm{Na}^{+}$e o $\mathrm{Mg}^{+2}$, que são bons indicativos de fontes naturais como as rochas cristalinas.

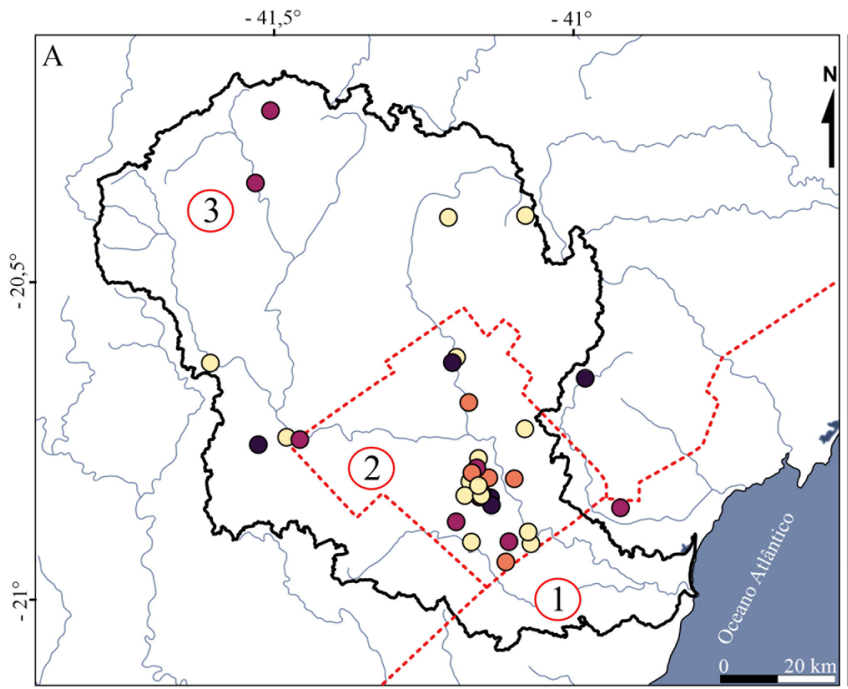

Distribuição espacial dos valores de $\mathrm{NO}_{3}^{-}\left(\mathrm{mg} \cdot \mathrm{L}^{-1}\right)$ $0<5$

o $10-20$

- $>20$

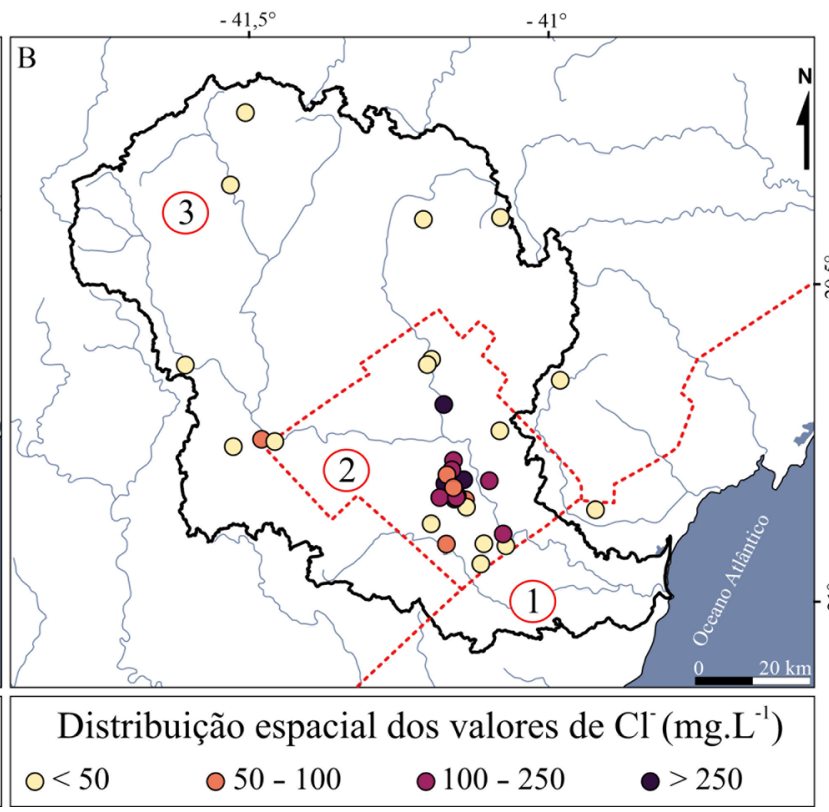

Figura 9. Distribuição espacial dos valores de $(\mathrm{A}) \mathrm{NO}_{3}^{-}$e (B) $\mathrm{Cl}^{-}$na Bacia Hidrográfica do Rio Itapemirim. A linha pontilhada vermelha delimita os compartimentos da Bacia Hidrográfica do Rio Itapemirim: (3) Alta BHRl; (2) Média BHRI e (1) Baixa BHRI.

Tabela 2. Matriz de correlação dos parâmetros hidrogeoquímicos analisados (valores em negrito indicam correlação positiva forte).

\begin{tabular}{|c|c|c|c|c|c|c|c|c|c|c|c|c|}
\hline & $\mathrm{pH}$ & CE & Turb. & $\mathrm{HCO}_{3}^{-}$ & $\mathrm{SO}_{4}{ }^{-2}$ & $\mathrm{HPO}_{4}{ }^{-2}$ & $\mathrm{Cl}^{-}$ & $\mathrm{NO}_{3}^{-}$ & $\mathrm{Na}^{+}$ & $\mathrm{K}^{+}$ & $\mathrm{Ca}^{+2}$ & $\mathrm{Mg}^{+2}$ \\
\hline $\mathrm{pH}$ & 1,0 & & & & & & & & & & & \\
\hline CE & 0,2 & 1,0 & & & & & & & & & & \\
\hline Turb. & 0,4 & 0,4 & 1,0 & & & & & & & & & \\
\hline $\mathrm{HCO}_{3}^{-}$ & 0,2 & 0,7 & 0,3 & 1,0 & & & & & & & & \\
\hline $\mathrm{SO}_{4}^{-2}$ & 0,1 & 0,7 & 0,1 & 0,7 & 1,0 & & & & & & & \\
\hline $\mathrm{HPO}_{4}^{-2}$ & 0,2 & $-0,2$ & $-0,2$ & $-0,2$ & $-0,1$ & 1,0 & & & & & & \\
\hline $\mathrm{Cl}^{-}$ & 0,1 & 0,9 & 0,3 & 0,3 & 0,3 & $-0,1$ & 1,0 & & & & & \\
\hline $\mathrm{NO}_{3}{ }^{-}$ & $-0,2$ & $-0,3$ & $-0,4$ & $-0,3$ & $-0,1$ & 0,1 & $-0,2$ & 1,0 & & & & \\
\hline $\mathrm{Na}^{+}$ & 0,2 & 1,0 & 0,3 & 0,7 & 0,7 & $-0,1$ & 0,8 & $-0,2$ & 1,0 & & & \\
\hline $\mathrm{K}^{+}$ & 0,2 & 0,5 & 0,3 & 0,2 & 0,3 & 0,0 & 0,4 & $-0,2$ & 0,5 & 1,0 & & \\
\hline $\mathrm{Ca}^{+2}$ & 0,0 & 0,9 & 0,3 & 0,5 & 0,4 & $-0,2$ & 0,9 & $-0,2$ & 0,8 & 0,3 & 1,0 & \\
\hline $\mathrm{Mg}^{+2}$ & 0,1 & 0,8 & 0,3 & 0,9 & 0,7 & $-0,2$ & 0,5 & $-0,3$ & 0,7 & 0,1 & 0,7 & 1,0 \\
\hline
\end{tabular}

CE: condutividade elétrica; Turb.: turbidez. 
$\mathrm{O} \mathrm{NO}_{3}^{-}$, parâmetro determinante para a identificação de agentes antrópicos na água subterrânea, está acima do padrão de potabilidade em apenas um poço (o de número 70). Embora a quase totalidade dos valores de $\mathrm{NO}_{3}^{-}$medidos estejam dentro do limite preconizado pela Portaria $\mathrm{n}^{\circ}$ 05/2017 (Brasil, 2017), consideram-se os níveis preocupantes, pois cerca de $30 \%$ das amostras possuem mais de $10 \mathrm{mg}$ $\mathrm{L}^{-1}$ de $\mathrm{NO}_{3}$. Durante a coleta, observou-se que as características construtivas dos poços são, muitas vezes, precárias (como atestado pela turbidez elevada), motivo pelo qual se acredita que a entrada de $\mathrm{NO}_{3}{ }^{-}$possa estar comprometendo a qualidade da água por infiltração de efluentes domésticos ou advindos de atividades pecuárias.

Para evitar interpretações equivocadas, as amostras com alta concentração de $\mathrm{NO}_{3}^{-}$(aqui consideradas aquelas com teores acima de $10 \%$ de $\mathrm{NO}_{3}^{-}$no balanço iônico) foram retiradas do conjunto de dados tratados na análise que segue, em que se busca verificar a origem dos principais constituintes iônicos de origem natural medidos na água subterrânea da BHRI.

\section{Classificação da água subterrânea e compartimentação hidrogeoquímica}

Os tipos hidroquímicos mais comuns na área são as águas bicarbonatadas sódicas e cloretadas sódicas, que predominam na porção da Média BHRI, enquanto na porção alta da bacia predominam as bicarbonatadas cálcicas e bicarbonatadas cálcicas-magnesianas (Figura 10). A tendência geral de mineralização da água é o incremento em íons a partir das regiões serranas, com cotas mais elevadas, para as porções

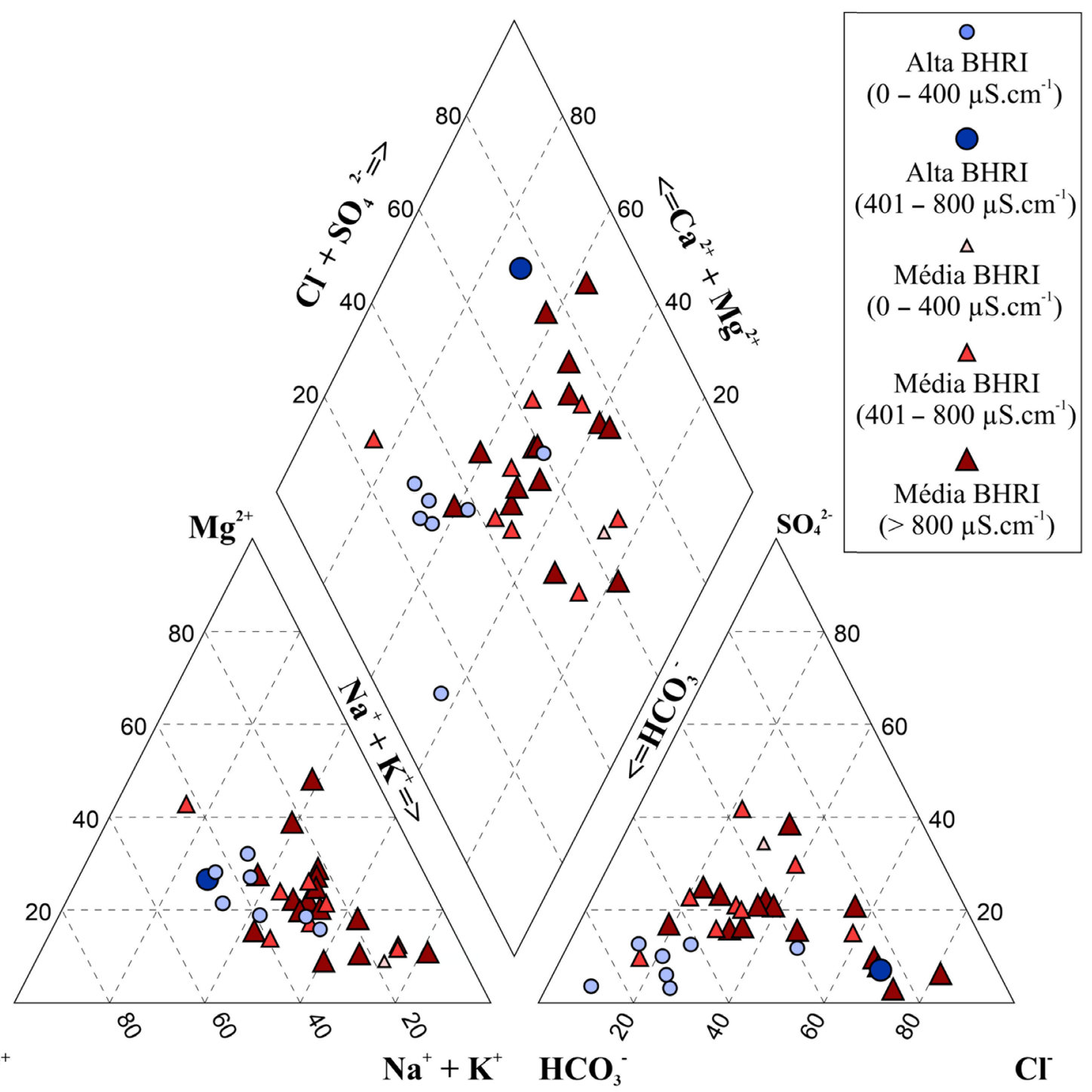

BHRI: Bacia Hidrográfica do Rio Itapemirim.

Figura 10. Classificação hidrogeoquímica das águas subterrâneas do meio fraturado na Bacia Hidrográfica do Rio Itapemirim. 
topograficamente mais baixas, junto à calha do Rio Itapemirim (Figura 11). Na porção Média da BHRI, que coincide com a zona climática mais seca e quente (Figura 3), ocorre enriquecimento mineral com valores máximos junto à área urbana de Cachoeiro de Itapemirim. Além das características climáticas, outro fator a ser considerado como influenciador dessa diferenciação hidrogeoquímica é a presença de rochas carbonáticas e calciossilicáticas nessa porção central da bacia, onde os íons tradicionalmente advindos de rochas cristalinas, como $\mathrm{Na}^{+}, \mathrm{Ca}^{+2}$ e $\mathrm{Mg}^{+2}$, são mais concentrados comparativamente à porção da Alta BHRI.

A diferenciação hidrogeoquímica entre os setores da BHRI também pode ser observada nas relações iônicas (Figura 12). Os elementos alcalinos terrosos $\left(\mathrm{Ca}^{+2} \mathrm{e} \mathrm{Mg}^{+2}\right)$ são predominantes na porção da Alta BHRI, enquanto na porção Média existem as duas situações: íons alcalinos $\left(\mathrm{Na}^{+} \mathrm{e} \mathrm{K}^{+}\right)$às vezes sobressaem, mas também há pontos com enriquecimento de alcalinos terrosos (Figura 12A). As relações entre $\mathrm{Cl}^{-}$e $\mathrm{SO}_{4}^{-2}$

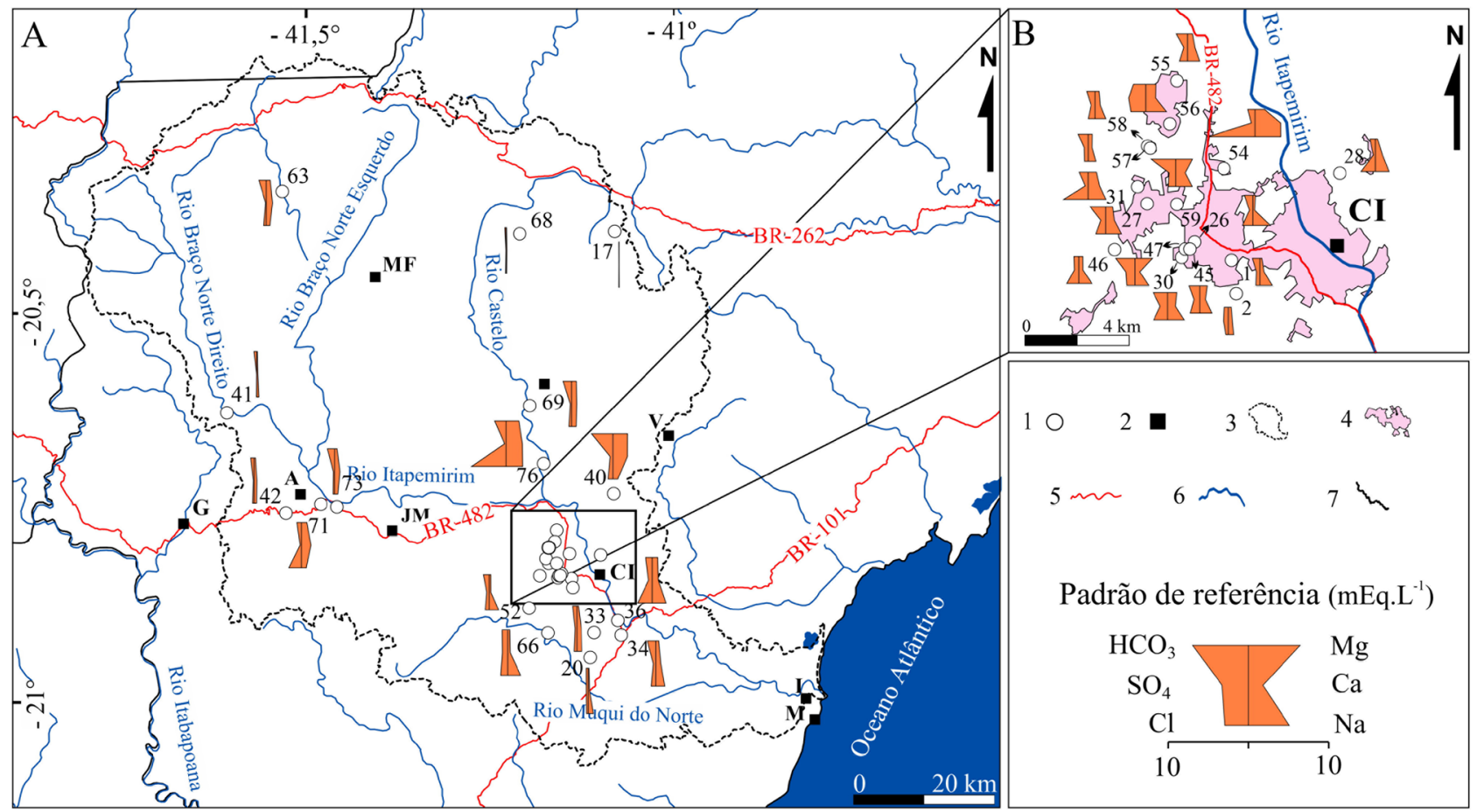

A: Alegre; G: Guaçuí; Cl: Cachoeiro de Itapemirim; I: Itapemirim; JM: Jerônimo Monteiro; M: Marataízes; MF: Muniz Freire; V: Venda Nova do Imigrante; 1: localização dos poços; 2: principais cidades; 3: limite da Bacia Hidrográfica do Rio Itapemirim; 4: área urbana; 5: principais rodovias; 6: hidrografia; 7: limites estaduais.

Figura 11. (A) Variação espacial das características hidrogeoquímicas da água subterrânea na Bacia Hidrográfica do Rio Itapemirim, com (B) detalhe na área urbanizada de Cachoeiro de Itapemirim.
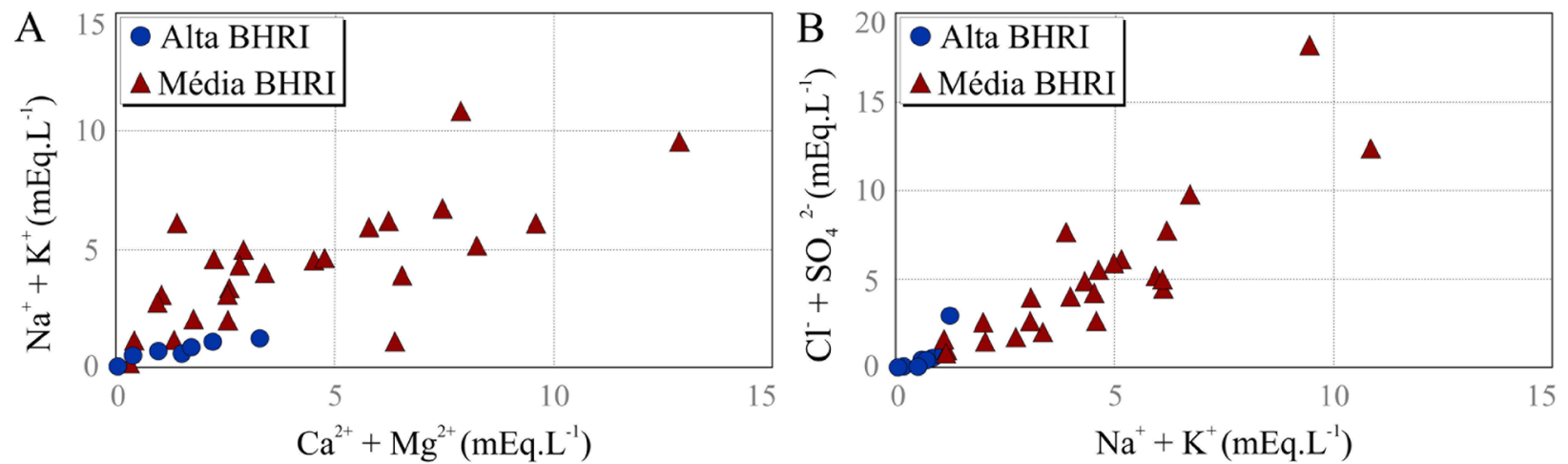

BHRI: Bacia Hidrográfica do Rio Itapemirim.

Figura 12. (A) Relação entre elementos alcalinos e alcalinos terrosos, e (B) entre ânions e elementos alcalinos na água subterrânea coletada na Alta e na Média Bacia Hidrográfica do Rio Itapemirim. 
e íons alcalinos $\left(\mathrm{Na}^{+} \mathrm{e} \mathrm{K}^{+}\right)$(Figura 12B) também mostram a maior mineralização na água subterrânea na Média BHRI, e na porção Alta os primeiros são menos presentes. Os íons $\mathrm{Cl}^{-} \mathrm{SO}_{4}^{-}$podem estar sendo concentrados pelo maior tempo de residência aliado a processos de evaporação na porção mais quente e seca da bacia hidrográfica.

Os índices geoquímicos que, de acordo com Hounslow (1995), podem indicar a origem dos íons presentes na água foram calculados e organizados na Tabela 3, de acordo com a porção Alta e Média da bacia e em ordem decrescente de valores dos índices, da esquerda para a direita.

O índice $\mathrm{Na}^{+} /\left(\mathrm{Na}^{+}+\mathrm{Cl}^{-}\right)$geralmente ficou acima de 0,5 , com exceção dos poços 71, 31, 54 e 76, que apresentaram

Tabela 3. Índices geoquímicos das águas coletadas em poços ao longo da Bacia Hidrográfica do Rio Itapemirim.

\begin{tabular}{|c|c|c|c|c|}
\hline \multirow[b]{2}{*}{ Poço } & \multirow[b]{2}{*}{$\begin{array}{c}\text { Porção } \\
\text { BHRI }\end{array}$} & \multicolumn{3}{|c|}{ Índice geoquímico } \\
\hline & & $\begin{array}{c}\mathrm{Na}^{+} / \\
\mathrm{Na}^{+}+\mathrm{Cl}^{-}\end{array}$ & $\begin{array}{c}\mathrm{Na}^{+}+\mathrm{K}^{+}-\mathrm{Cl}^{-} \\
/ \mathrm{Na}^{+}+\mathrm{K}^{+}- \\
\mathrm{Cl}^{-}+\mathrm{Ca}^{2+}\end{array}$ & $\begin{array}{c}\mathrm{Ca}^{2+} / \mathrm{Ca}^{2+} \\
+\mathrm{SO}_{4}^{-2}\end{array}$ \\
\hline 41 & Alta & 0,89 & 0,64 & 0,91 \\
\hline 73 & Alta & 0,70 & 0,32 & 0,81 \\
\hline 42 & Alta & 0,68 & 0,38 & 0,80 \\
\hline 69 & Alta & 0,65 & 0,32 & 0,81 \\
\hline 68 & Alta & 0,59 & 0,32 & 0,94 \\
\hline 63 & Alta & 0,59 & 0,19 & 0,91 \\
\hline 17 & Alta & 0,54 & 0,27 & 0,74 \\
\hline 71 & Alta & 0,29 & $-2,18$ & 0,88 \\
\hline 1 & Média & 0,76 & 0,68 & 0,55 \\
\hline 57 & Média & 0,76 & 0,65 & 0,56 \\
\hline 20 & Média & 0,74 & 0,73 & 0,38 \\
\hline 52 & Média & 0,71 & 0,77 & 0,42 \\
\hline 59 & Média & 0,70 & 0,50 & 0,59 \\
\hline 2 & Média & 0,69 & 0,43 & 0,46 \\
\hline 34 & Média & 0,67 & 0,49 & 0,68 \\
\hline 66 & Média & 0,66 & 0,74 & 0,33 \\
\hline 56 & Média & 0,65 & 0,58 & 0,36 \\
\hline 33 & Média & 0,65 & 0,37 & 0,70 \\
\hline 30 & Média & 0,64 & 0,56 & 0,35 \\
\hline 26 & Média & 0,63 & 0,83 & 0,33 \\
\hline 27 & Média & 0,63 & 0,44 & 0,65 \\
\hline 58 & Média & 0,61 & 0,44 & 0,55 \\
\hline 55 & Média & 0,61 & 0,38 & 0,66 \\
\hline 45 & Média & 0,56 & 0,37 & 0,49 \\
\hline 47 & Média & 0,55 & 0,30 & 0,51 \\
\hline 46 & Média & 0,53 & 0,32 & 0,48 \\
\hline 40 & Média & 0,51 & 0,03 & 0,84 \\
\hline 28 & Média & 0,50 & 0,03 & 0,77 \\
\hline 36 & Média & 0,49 & $-0,05$ & 0,62 \\
\hline 31 & Média & 0,43 & $-0,86$ & 0,80 \\
\hline 54 & Média & 0,36 & $-3,41$ & 0,87 \\
\hline 76 & Média & 0,34 & $-17,33$ & 0,92 \\
\hline
\end{tabular}

valores mais baixos (Tabela 3). Na classificação de Hounslow (1995), valores maiores do que 0,5 indicam que a origem do $\mathrm{Na}^{+}$pode estar na dissolução do plagioclásio, mineral comum em terrenos granito-gnáissicos. Por outro lado, valores menores ou iguais a 0,5 indicariam dissolução de halita ou intrusão de água do mar. Como tais possibilidades não existem nessa parte da área, aventa-se a influência de águas da chuva provinda do oceano e o enriquecimento por evaporação no solo. Na porção da Média BHRI, a situação topográfica provoca menores gradientes hidráulicos e as condições climáticas são mais quentes e secas do que no entorno (Figura 3), fatores que poderiam contribuir de maneira efetiva para a concentração mineral da água subterrânea.

O índice $\left(\mathrm{Na}^{+}+\mathrm{K}^{+}-\mathrm{Cl}\right) /\left(\mathrm{Na}^{+}+\mathrm{K}^{+}-\mathrm{Cl}^{-}+\mathrm{Ca}^{+2}\right)$ pode indicar o tipo de mineral que governa a composição química da água de um aquífero. Valores entre 0,2 e 0,8 apontam para enriquecimento por alteração de plagioclásio, e abaixo de 0,2 , dissolução de carbonatos. A maioria das amostras coletadas na Alta BHRI pertence ao primeiro caso, enquanto na Média BHRI, valores abaixo de 0,2 são mais comuns (Tabela 3). Nos poços situados em substrato carbonático, esse índice é menor que 0,2 , comprovando a influência dos mármores na qualidade local da água subterrânea.

A relação $\mathrm{Ca}^{+2} /\left(\mathrm{Ca}^{+2}+\mathrm{SO}_{4}^{-2}\right)$ acima de 0,5 indica dissolução de silicatos e carbonatos, enquanto valores abaixo de $0,5 \mathrm{em} \mathrm{pH}$ neutro apontam para a remoção de $\mathrm{Ca}^{+2}$ da solução por troca iônica ou precipitação de calcita, que é o caso predominante na área. Na Alta BHRI, essa relação ficou sempre acima de 0,5 , enquanto na Média BHRI predominam valores menores que 0,5 (Tabela 3 ). Como não há fonte de $\mathrm{SO}_{4}^{-2}$ nos terrenos cristalinos da região, acredita-se que os valores baixos desse índice na Média BHRI reflitam a reconcentração iônica por evaporação da água que infiltra no solo, associada ao maior tempo de residência, comparativamente com a porção da Alta BHRI.

Esses índices mostram, portanto, que a composição litológica também deve ser considerada como influenciadora da composição iônica da água subterrânea na porção da Média BHRI. Nesse sentido, um mapeamento geológico de detalhe seria fundamental para a prospecção hidrogeológica na região, pois os mapas disponíveis atualmente são de escala 1:400.000 (Vieira et al., 2014), 1:250.000 (Vieira et al., 1997) e 1:100.000 (Silva, 1993), e o ideal para esse tipo de análise seria um mapa em escala de 1:50.000 ou de maior detalhe.

\section{DISCUSSÃO}

A compartimentação geomorfológica e as condições climáticas da BHRI apresentam relação espacial, e esse condicionamento também é observado nas variações das características hidrogeoquímicas. Na Alta BHRI, predominam 
águas bicarbonatadas cálcicas e cálcicas-magnesianas, pouco mineralizadas, enquanto na Média BHRI as águas tendem a ser mais cloretadas sódicas e bicarbonatadas sódicas, com maior grau de mineralização.

A porção da Alta BHRI, com relevo acidentado e manto de intemperismo pouco espesso, tende a propiciar menor tempo de residência da água subterrânea. Ao contrário, na porção da Média BHRI, o manto de intemperismo mais espesso e os declives mais suaves devem promover maior tempo de residência e maior taxa de evaporação nas zonas de recarga. Pesquisas anteriores indicam que na porção da Alta BHRI há solos rasos e grandes áreas de rocha exposta, que fornecem sedimentos para as porções mais baixas da bacia (Peixoto-Oliveira et al., 2018). Dessa forma, a espessura do manto de intemperismo nas porções da Média e da Baixa BHRI tende a ser mais espessa do que nas porções mais elevadas da bacia, que compõem áreas de degradação, ou seja, fornecem sedimentos para as áreas de agradação representadas pelas porções de topografia mais baixa.

Segundo Larsson (1985), a evaporação da água em infiltração no solo aumenta a concentração dos elementos dissolvidos, e esse é o processo que mais influencia o conteúdo salino das águas subterrâneas em terrenos de rochas cristalinas, particularmente quanto ao cloreto de sódio. $\mathrm{Na}$ área aqui estudada, permanece uma dúvida com relação à fonte de $\mathrm{Cl}^{-}$, que contribui para a salinização da água subterrânea na Média BHRI, junto a outros elementos geralmente fornecidos pelo intemperismo das rochas. Há possibilidade de proveniência do $\mathrm{Cl}^{-}$a partir de água do mar trazida pelas chuvas que, ao caírem no solo, sofrem evaporação e enriquecem a água de recarga, conforme observado em outros lugares do mundo (e.g. Neal e Kirchner, 2000; Stoecker et al., 2013).

A compartimentação hidroquímica observada na BHRI está de acordo com relatos de vários autores que estudam a hidrogeologia em terrenos cristalinos, onde a espessura do perfil de solo e a topografia são considerados fatores que afetam o runoff (ou escoamento superficial) e interferem diretamente na recarga do sistema de fraturas subjacente (e.g. Henriksen, 1995). Esse sistema de fraturas pode transmitir água por grandes distâncias e é também reabastecido por meio de recarga local, a partir de circulação rasa (Bochet et al., 2020).

Outro fator relevante observado na BHRI é a tendência geral do fluxo da água subterrânea, que pode ser considerado como característico de bacias de relevo acidentado. Alguns autores (Praamsma et al., 2009; Roques et al., 2014) mostram que existem sistemas de recarga local e regional em terrenos de rocha cristalina. Resultados de Boutt et al. (2010) sugerem que, nesse tipo de ambiente geológico, os sistemas de fluxo ativo são rasos e a permeabilidade de fraturas decresce com a profundidade, exceto em locais com estruturas de grande escala. Assim, a recarga ocorre ao longo de áreas com manto de intemperismo, que abastece os sistemas de fraturas de circulação profunda, provenientes de locais mais distantes, onde ocorre a mistura das águas (Bochet et al., 2020). Esse tipo de estrutura pode ocorrer na área de estudos ao longo das zonas de cisalhamento pré-cambrianas, tal como a Zona de Cisalhamento Guaçuí, que constitui descontinuidades crustais reativadas em regime rúptil, gerando zonas fraturadas (Calegari et al., 2020).

Misturas de águas de diferentes regiões da bacia podem ser encontradas nos locais para onde os fluxos convergem, os quais, em termos hidrográficos, tendem a ser o eixo de drenagem principal da bacia. Tais fatores, por si só, poderiam ser apontados como responsáveis pela maior mineralização das águas na porção da Média BHRI. Porém, as condições climáticas mais quentes e secas nessa porção da bacia acentuam tais efeitos, os quais, aliados às ocorrências de rochas carbonáticas, causam as mudanças hidrogeoquímicas.

Salienta-se que este estudo envolveu períodos de pluviosidade anomalamente baixa, entre os anos de 2014 e 2016; é recomendável, portanto, a continuidade do monitoramento da qualidade da água subterrânea na região.

\section{CONCLUSÕES}

A tendência geral da água subterrânea na BHRI é a menor mineralização nas regiões topograficamente elevadas e o aumento da concentração iônica rumo às porções mais baixas da bacia. A distribuição dos tipos hidroquímicos acompanha a compartimentação geológica e geomorfológica regional: na porção da Alta BHRI ocorrem águas bicarbonatadas cálcicas e bicarbonatadas cálcicas-magnesianas, e na Média BHRI, predominam as cloretadas sódicas e bicarbonatadas sódicas. Na região da Alta BHRI, a composição química da água subterrânea é governada essencialmente pelo intemperismo das rochas silicáticas. Por outro lado, na Média BHRI, as características hidroquímicas são influenciadas também pela presença de rochas carbonáticas, como mármores e calciossilicáticas. As condições climáticas, com temperaturas mais altas e menor umidade do ar na área central da bacia, topograficamente mais rebaixada, também podem contribuir com o enriquecimento mineral em decorrência da evaporação da água que infiltra no solo.

\section{AGRADECIMENTOS}

Os autores agradecem à Financiadora de Estudos e Projetos (FINEP - convênio 01.10.0808.00) o apoio financeiro ao desenvolvimento deste trabalho. 


\section{REFERÊNCIAS}

Agência Nacional de Águas (ANA). (2010). Bacias do Atlântico Sudeste. Disponível em: https://www.gov.br/ ana/pt-br/as-12-regioes-hidrograficas-brasileiras/atlanticosudeste. Acesso em: 4 nov. 2021.

Banks, E. W., Simmons, C. T., Love, A. J., Cranswick, R., Werner, A. D., Bestland, E. A., Wood, M., Wilson, T. (2009). Fractured bedrock and saprolite hydrogeologic controls on groundwater/surface-water interaction: a conceptual model (Australia). Hydrogeology Journal, 17, 1969-1989. https:// doi.org/10.1007/s10040-009-0490-7

Bochet, O., Bethencourt, L., Dufresne, A., Farasin, J., Pédrot, M., Labasque, T., Chatton, E., Lavenant, N., Petton, C., Abbot, B. W., Aquilina, L., Le Borgne, T. (2020). Ironoxidizer hotspots formed by intermittent oxic-anoxic fluid mixing in fractured rocks. Nature Geoscience, 13, 149-155. https://doi.org/10.1038/s41561-019-0509-1

Boutt, D. F., Diggins, P., Mabee, S. (2010). A field study (Massachusetts, USA) of the factors controlling the depth of groundwater flow systems in crystalline fractured-rock terrain. Hydrogeology Journal, 18(8), 1839-1854. https:// doi.org/10.1007/s10040-010-0640-y

Brasil. Ministério da Saúde. (2017). Portaria $n^{\circ} 5$, de 28 de setembro de 2017. Disponível em: http://bvsms.saude. gov.br/bvs/saudelegis/gm/2017/prc0005_03_10_2017.html. Acesso em: 29 abr. 2019.

Bucher, K., Zhu, Y., Stober, I. (2009). Groundwater in fractured crystalline rocks, the Clara mine, Black Forest (Germany). International Journal of Earth Science (Geol Rundsch), 98, 1727-1739. https://doi.org/10.1007/s00531-008-0328-x

Calegari, S. S., Aiolfi, T. R., Neves, M. A., Soares, C. C., Marques, R. A., Caxito, F. (2020). Filling materials in brittle structures as indicator of Cenozoic tectonic events in Southeastern Brazil. Anuário do Instituto de Geociências da UFRJ, 43(2), 237254. https://doi.org/10.11137/2020_2_237_254

Ezaki, S., Oda, G. H., Iritani, M. A., Veiga, C., Stradioto, M. R. (2014). Hidroquímica dos aquíferos Tubarão e Cristalino na região de Indaiatuba-Rafard, Estado de São Paulo. Pesquisas em Geociências, 41(1), 65-79. https://doi. org/10.22456/1807-9806.78036

Foster, S. (2012). Hard-rock aquifers in tropical regions: using science to inform development and management policy. Hydrogeology Journal, 20, 659-672. https://doi. org/10.1007/s10040-011-0828-9
Geobases. (2002). Bases Cartográficas do Espirito Santo. Disponível em: http://www.geobases.es.gov.br/. Acesso em: 29 abr. 2019.

Gomes, M. C. R., Cavalcante, I. N. (2015). Análise geoquímica das águas subterrâneas de Fortaleza, Ceará - Brasil. Águas Subterrâneas, 29(1), 42-59. https://doi.org/10.14295/ras. v29i1.27917

Gradim, C., Roncato, J., Pedrosa-Soares, A. C., Cordani, U., Dussin, I., Alkmim, F. F., Queiroga, G., Jacobsohn, T., Silva, L. C., Babinski, M. (2014). The hot backarc zone of the Araçuaí orogen, Eastern Brazil: from sedimentation to granite generation. Brazilian Journal of Geology, 44(1), 155-180. https://doi.org/10.5327/ Z2317-4889201400010012

Hem, J. D. (1985). Study and interpretation of chemical characteristics of natural water. 3. ed. USGS - United States Geological Survey. Disponível em: https://pubs. usgs.gov/wsp/wsp2254/pdf/wsp2254a.pdf. Acesso em: 14 set. 2021.

Henriksen, H. (1995). Relation between topography and well yield in boreholes in crystalline rocks, Sogn og Fjordane, Norway. Ground Water, 33(4), 635-643. https:// doi.org/10.1111/j.1745-6584.1995.tb00319.x

Hounslow, A. W. (1995). Water quality data. Nova York e Boca Raton: Lewis Publishers.

Instituto Brasileiro de Geografia e Estatística (IBGE). (2010). Censo demográfico de 2010. Disponível em: https:// censo2010.ibge.gov.br/sinopse/index.php?uf $=32 \&$ dados $=0$. Acesso em: 2 jun. 2018.

Instituto Capixaba de Pesquisa, Assistência e Extensão Rural (INCAPER). (2016). Anomalia de Precipitação 2016. Disponível em: https://meteorologia.incaper.es.gov. $\mathrm{br} /$ mapas-de-chuva-anomalia-mensal-e-anual-2016. Acesso em: 30 jan. 2020.

Instituto Capixaba de Pesquisa, Assistência e Extensão Rural (INCAPER). (2018). Precipitação Observada-2018. Disponível em: https://meteorologia.incaper.es.gov.br/ mapas-de-chuva-acumulado-mensal-e-anual-2018. Acesso em: 12 fev. 2020.

Iritani, M. A., Yoshinaga-Pereira, S., Ezaki, S., Oda, G. H., Ferreira, L. M. R. (2011). Caracterização hidroquímica das águas subterrâneas no Município de Itu (SP). Revista do Instituto Geológico, 32(1-2), 11-26. https://doi. org/10.5935/0100-929X.20110002 
Lachassagne, P., Wyns, R., Dewandel, B. (2011). The fracture permeability of Hard Rock Aquifers is due neither to tectonics, nor to unloading, but to weathering processes. Terra Nova, 23(3), 145-161. https://doi. $\operatorname{org} / 10.1111 / \mathrm{j} .1365-3121.2011 .00998 . x$

Larsson, I. (1985). Aguas subterráneas en Rocas Duras. Proyecto 8.6 del Programa Hidrologico Internacional. Disponível em: https://unesdoc.unesco.org/ark:/48223/ pf0000063230_spa. Acesso em: 12 fev. 2020.

Machiwal, D., Jha, M. (2015). Identifying sources of groundwater contamination in a hard-rock aquifer system using multivariate statistical analyses and GIS-based geostatistical modeling techniques. Journal of Hydrology: Regional Studies, 4(Parte A), 80-110. https://doi.org/10.1016/j.ejrh.2014.11.005

Menezes, J. M., Silva Júnior, G. C., Santos, R. T. (2008). Hidrogeoquímica de aquíferos fraturados: estudo de caso na bacia hidrográfica do Rio São Domingos, noroeste do estado do Rio de Janeiro. Águas Subterrâneas, 22(1), 75-90. https://doi.org/10.14295/ras.v22i1.8614

Neal, C., Kirchner, J. W. (2000). Sodium and chloride levels in rainfall, mist, streamwater and groundwater at the Plynlimon catchments, mid-Wales: inferences on hydrological and chemical controls. Hydrology and Earth System Sciences, 4(2), 295-310. https://doi.org/10.5194/hess-4-295-2000

Negrel, P., Pauwels, H., Dewandel, B., Gandolfi, J. M., Mascré, C., Ahmed, S. (2011). Understanding groundwater systems and their functioning through the study of stable water isotopes in a hard-rock aquifer (Maheshwaram watershed, India). Journal of Hydrology, 397(1-2), 55-70. https://doi.org/10.1016/j.jhydrol.2010.11.033

Peixoto-Oliveira, J., Neves, M. A., Calegari, S. S., Guadagnin, F. (2018). Compartimentação morfoestrutural da Bacia Hidrográfica do Rio Itapemirim, Sul do Estado do Espírito Santo. Geologia USP. Série Cientifica, 18(2), 57-70. https:// doi.org/10.11606/issn.2316-9095.v18-134749

Praamsma, T., Novakowski, K., Kyser, K., Hall, K. (2009). Using stable isotopes and hydraulic head data to investigate groundwater recharge and discharge in a fractured rock aquifer. Journal of Hydrology, 366(1-4), 35-45. https://doi. org/10.1016/j.jhydrol.2008.12.011

Raju, N. J., Patel, P., Reddy, B. C. S. R., Suresh, U., Reddy, T. V. K. (2016). Identifying source and evaluation of hydrogeochemical processes in the hard rock aquifer system: geostatistical analysis and geochemical modeling techniques. Environmental Earth Sciences, 75, 1157. https:// doi.org/10.1007/s12665-016-5979-5
Roques, C., Aquilina, L., Bour, O., Maréchal, J. C., Dewandel, B., Pauwels, H., Labasque, T., Vergnaud-Ayraud, V., Hochreutener, R. (2014). Groundwater sources and geochemical processes in a crystalline fault aquifer. Journal of Hydrology, 519(Parte D), 3110-3128. https://doi.org/10.1016/j. jhydrol.2014.10.052

Sardou-Filho, R., Matos, G. M. M., Mendes, V. A., Iza, E. R. H. F. (2013). Atlas de rochas ornamentais do estado do Espirito Santo. CPRM. 352 p. Disponível em: https://rigeo. cprm.gov.br/handle/doc/17787. Acesso em: 14 set. 2021.

Secretaria de Estado do Planejamento (SEPLAN). (1999). Zonas naturais do Espírito Santo: uma regionalização do Estado, das microrregiões e dos municípios. Vitória: SEPLAN.

Silva, J. N. (1993). Programa levantamentos geológicos básicos do Brasil: Cachoeiro de Itapemirim. Folha SF.24V-A-V. Estado do Espírito Santo. Escala 1:100.000. Brasília: DNPM/CPRM. 176 p. 2 mapas. Disponível em: https://rigeo. cprm.gov.br/handle/doc/13671. Acesso em: 14 set. 2021.

Singaraja, C., Chidambaram, S., Prasanna, M. V., Thivya, C., Thilagavathi, R. (2014). Statistical analysis of the hydrogeochemical evolution of groundwater in hard rock coastal aquifers of Thoothukudi district in Tamil Nadu, India. Environmental Earth Sciences, 71, 451-464. https:// doi.org/10.1007/s12665-013-2453-5

Singhal, B. B. S., Gupta, R. P. (2010). Applied hydrogeology of fractured rocks. 2. ed. Holanda: Springer, 408 p. https:// doi.org/10.1007/978-90-481-8799-7

Srinivasamoorthy, K., Chidambaram, S., Prasanna, M. V., Vasanthavihar, M., Peter, J., Anandhan, P. (2008). Identification of major sources controlling groundwater chemistry from a hard rock terrain - a case study from Mettur taluk, Salem district, Tamil Nadu, India. Journal of Earth System Science, 117(1), 49-58. https://doi.org/10.1007/ s12040-008-0012-3

Stoecker, F., Babel, M. S., Gupta, A. D., Rivas, A. A., Evers, M., Kazama, F., Nakamura, T. (2013). Hydrogeochemical and isotopic characterization of groundwater salinization in the Bangkok aquifer system, Thailand. Environmental Earth Science, 68, 749-763. https://doi.org/10.1007/ s12665-012-1776-y

Subramani, T., Rajmohan, N., Elango, L. (2010). Groundwater geochemistry and identification of hydrogeochemical processes in a hard rock region, Southern India. Environmental Monitoring and Assessment, 162, 123-137. https://doi. org/10.1007/s10661-009-0781-4 
Thivya, C., Chidambaram, S., Thilagavathi, R., Prasanna, M. V., Singaraja, C., Adithya, V. S., Nepolian, M. (2015). A multivariate statistical approach to identify the spatiotemporal variation of geochemical process in a hard rock aquifer. Environmental Monitoring and Assessment, 187, 552. https://doi.org/10.1007/s10661-015-4738-5

United States National Aeronautics and Space Administration (NASA), Ministry of Economy, Trade and Industry of Japan (METI). (2011). ASTER GDEM v2 Advanced Spaceborne Thermal Emission and Reflection Radiometer (ASTER) Global Digital Elevation Model Version 2. Disponível em: https://earthexplorer.usgs.gov. Acesso em: 20 abr. 2018.
Vieira, V. S., Rapozo, F.O., Souza, E. C., Marques, M. (1997). Projeto Mapeamento Geológico: Programa Levantamentos Geológicos Básicos. Folha Cachoeiro do Itapemirim (SF 24-V-A). Escala 1:250.000. CPRM - Serviço Geológico do Brasil. Disponível em: https:// rigeo.cprm.gov.br/handle/doc/8745. Acesso em: 14 set. 2021.

Vieira, V. S., Silva, M. A., Corrêa, T. R., Lopes, M. H. B. (2014). Mapa Geológico do Espírito Santo em Escala 1:400.000. Companhia de Pesquisa de Recursos Minerais (CPRM). Disponível em: http://geosgb.cprm.gov.br/geosgb/ downloads.html. Acesso em: 20 abr. 2018. 